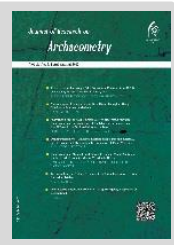

\title{
The First Obsidian Source in North-Western Iran for Provenance of Local Prehistoric Lithic Artifacts
}

\author{
Akbar Abedi ${ }^{1 *}$, Bahram Vosough ${ }^{2}$, Mehdi Razani ${ }^{1}$, Masoud Bagherzadeh Kasiri ${ }^{1}$, \\ Daniel Steiniger ${ }^{3}$, Ghader Ebrahimi ${ }^{4}$ \\ ${ }^{1}$ Archaeometry Department, Tabriz Islamic Art University, Tabriz, IRAN \\ ${ }^{2}$ Geology Department, Payam-e Noor University, Tabriz, IRAN \\ ${ }^{3}$ Deutsches Archäologisches Institut, Eurasien Abteilung, Archaeology Department, GERMANY \\ ${ }^{4}$ Mohagegh Ardabili University, Ardabil, IRAN
}

Received: $26 / 10 / 2017$

Accepted: 19/06/2019

\begin{abstract}
Obsidian is a dark glass formed by very rapid solidification of volcanic lava, but in the archaeological view, this volcanic glass is an important source for prehistoric tool-making and artifacts such as arrowhead, point, flake, blade, hand axes, micro-blades and etc. Therefore, obsidian artifacts are frequently used material in prehistory and found widely in archaeological sites around the world. The provenance study of obsidian has been an issue of intense research and debate between archeaometrist and geologists. Hence, different provenance studies carried out in Anatolia and Caucasus since 1960s up to 2015, but the obsidian research in Iran is in very early stage and consider as terra incognita. According to the occurrence of lithic obsidian artifacts in most of the prehistoric archaeological sites in north-west of Iran have been recovered during last decades, various questions have been rise on the subject of the provenance of these materials. New studies on prehistoric obsidian artifacts have been done by other scholar specially Iranians during the recent years, where the main part of these studies focus on the characterization and classification of the obsidian artifacts by chemical analysis, in order to find an evidence of sourcing and provenance. More recent research showed that some obsidian tools might have come from unknown sources located in Iran (perhaps Sahand and Sabalan Mountain). This paper will try to discuss the new obsidian mine in north-west Iran in western Asia. After a brief introduction of obsidian studies in north-west Iran, the paper addresses preliminary report of recent researches that took place concerning 10 local obsidian mine samples from Tajaraq of Miyaneh and Ghizilja of Bostababad, around of Bozghoosh Mountain in the skirt of Sahand volcano. This study was

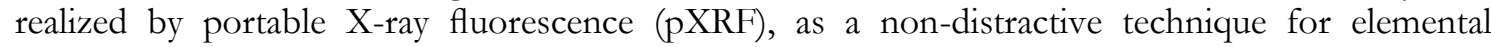
analysis, to differentiate between local obsidian mine. From 10 mine samples, 8 samples from Tajaraq of Miyaneh and 2 samples of Ghizilja of Bostanabad were selected and analyzed. This mine samples could be consider as the first obsidian source specimens in association with prehistoric lithic artifacts of north-west Iran and give the chance for detail and comparative studies of these sources with prehistoric site artifacts for provenance studies, as local or imported materials to this part of Iran. The research has been carried out with a focus on locating the origins and resources of obsidian procurement in the northwest of Iran, in order to rethink and reconstruct the regional and supra-regional trade and exchange networks in future. The project clearly identified the three groups of geochemically different obsidians named Tajaraq A, Tajaraq B, and Ghizilja. Due to the fact that Tajaraq obsidian is of a higher quality than the Ghizilja ones, it seems likely that the
\end{abstract}

*Corresponding author: akbar.abedi@tabriziau.ac.ir 
samples of Tajaraq obsidians have had the ability to be used for tool-making in the past, as the samples of Ghizilja, Bostanabad are too fragile and perlitic in structure. Hence, as the two groups of Tajaraq A and Tajaraq B have the ability to be used for ancient tools in all probability, they can be introduced as candidates for obsidian mining in prehistoric times in the northwest of Iran. In fact, the proposed hypothesis is still at a very early stage and future scientific studies and field research have to be followed. Comparing the new results with prehistoric sites in the cultural areas of Miyaneh and Bostanabad, it becomes obvious that the Tajaraq B obsidian overlaps in some trace elements with published data Anatolian sources. If this overlap could be found also by comparing other elements and their combination, and if it will be confirmed by other methods in future, it could lead to a complete review of all previous obsidian analysis from Iran. In other words, several samples that were up to now thought to be from Anatolia could come in reality from source B of Tajaraq. This is a serious and peculiar hypothesis, which means, at first step, more data have to be collected at the geological outcrops and especially, by analyzing the archaeological finds from well stratified context. The implications of the findings will discuss along with limitations and future research directions.

Keywords: Obsidian, Local Sources, XRF, Tajaraq Obsidian Mine, Ghizilja Mine, Bostanabad 


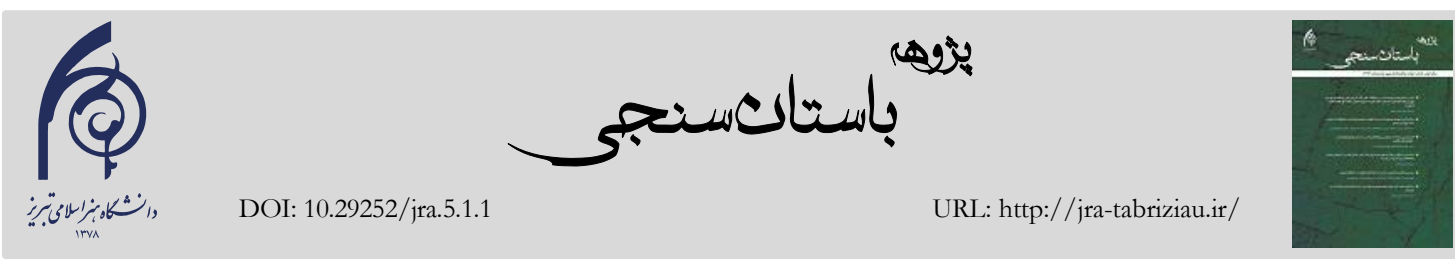

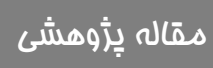

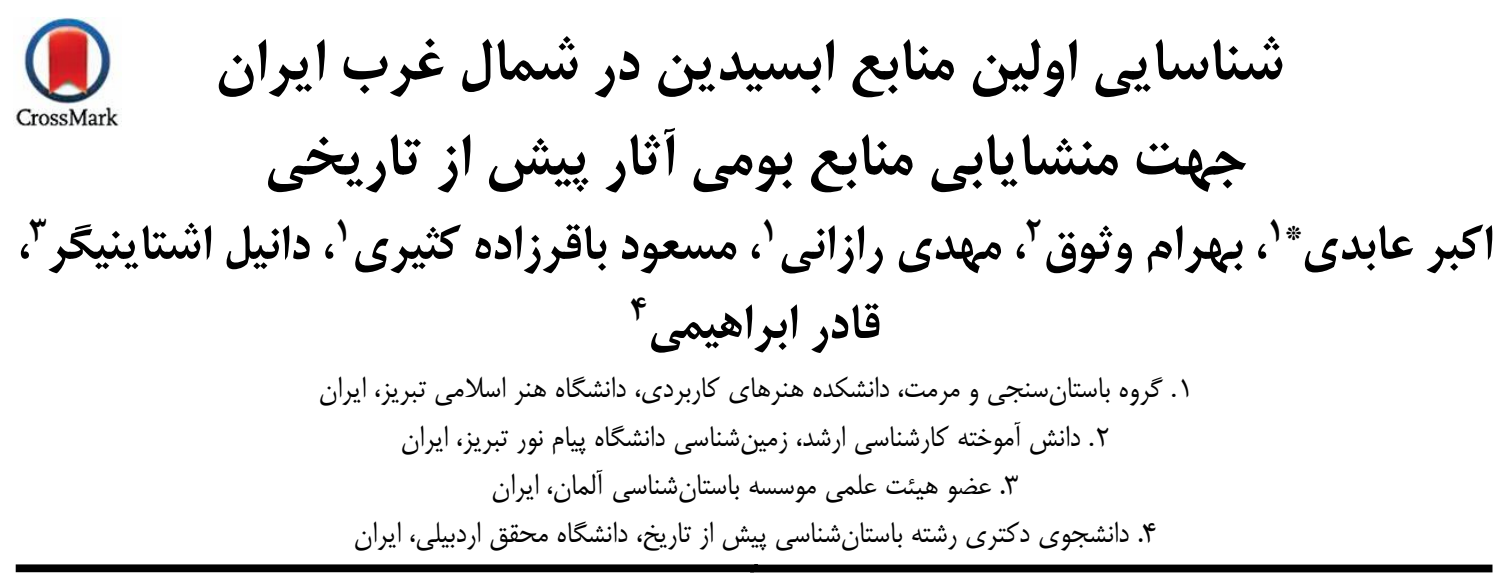

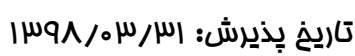

تاريخ دريافت: عاس

جكيده

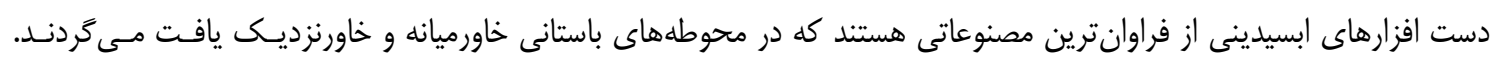

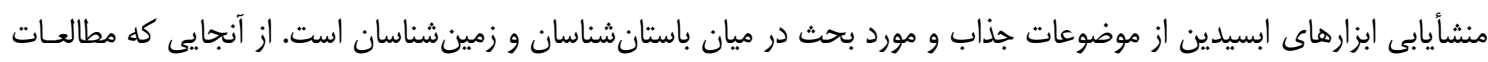

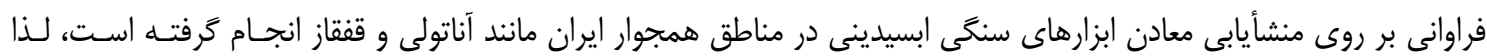

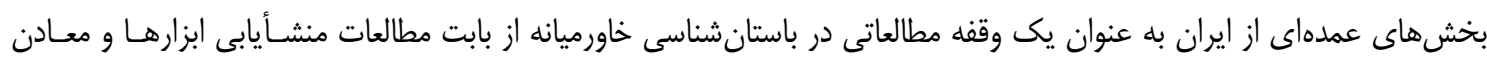

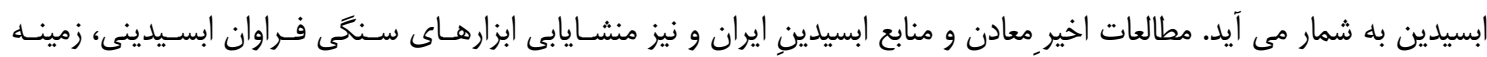

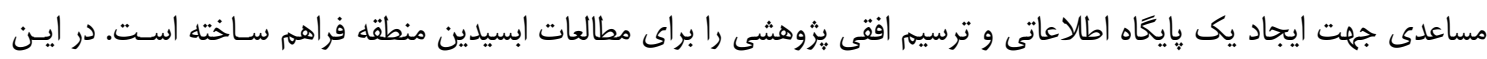

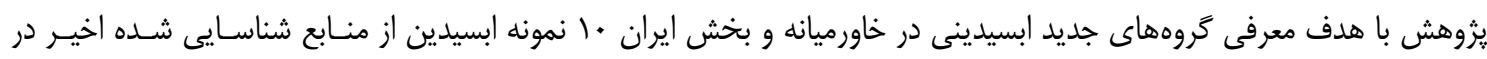

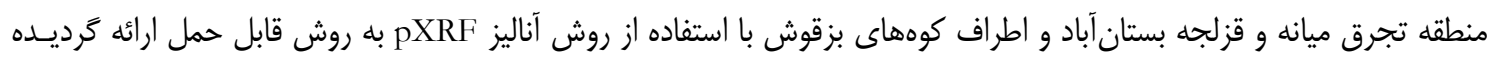

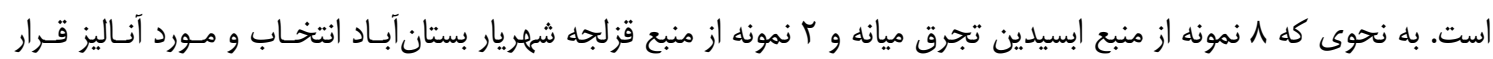

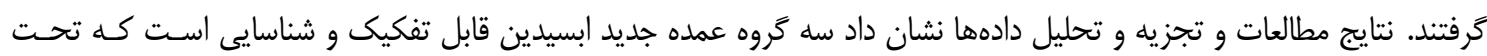

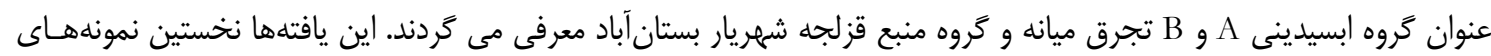

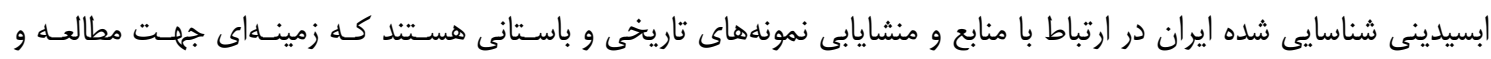

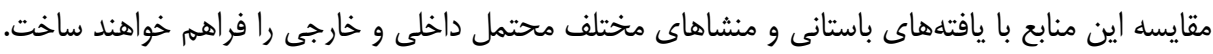

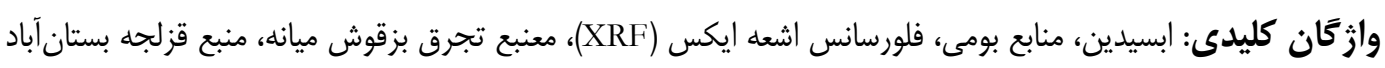

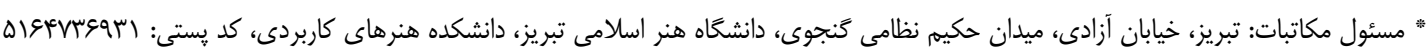

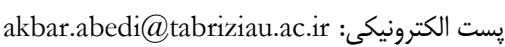

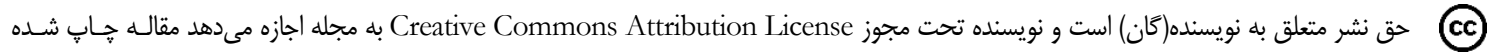

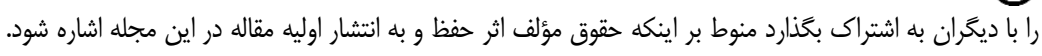


هاى مختلف در محلها و محوطههاى آتشفشانى مشابه مى توانند داراى ساختارهاى شـيميايى متفـاوتى باشــند،

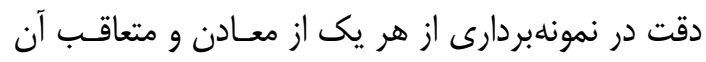

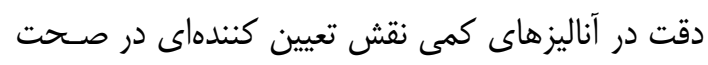

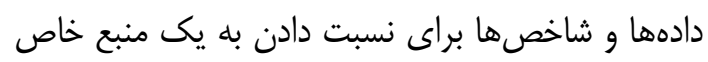

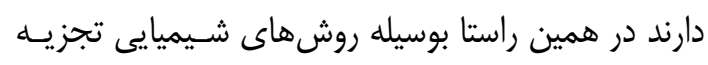
عنصرى مى توان تمامى نمونههاى ابسيدينى يافته شده

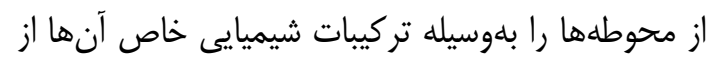
لحاظ زمينشناختى منشأيابى كرد [4].

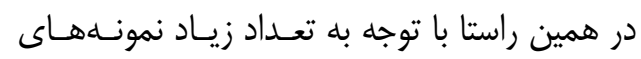

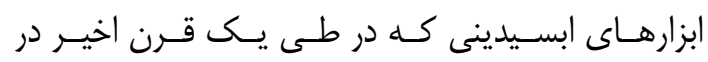

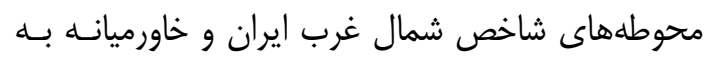
دست آمده است سـوالات بسـيارى در رابطـهـه بـا منشـا

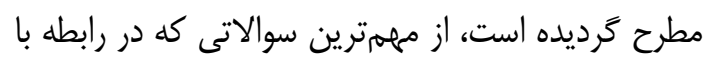

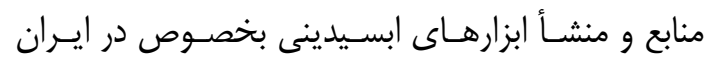

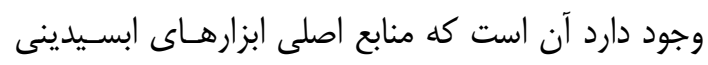

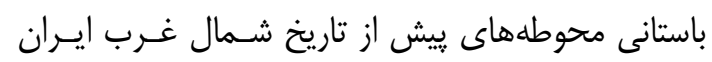

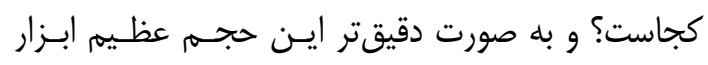

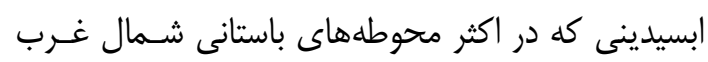

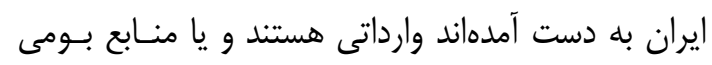

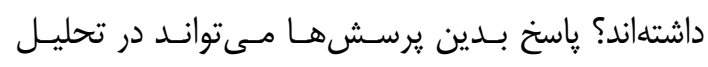

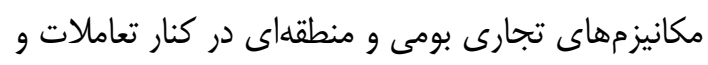

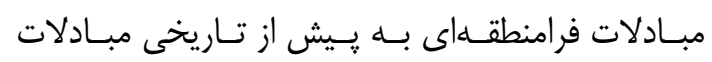

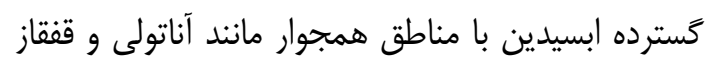

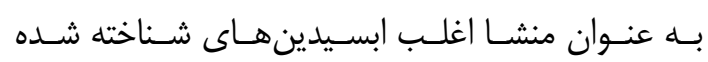
خاورميانه در دوران ييش از تاريخ وجود بسيار تاثير حـزار

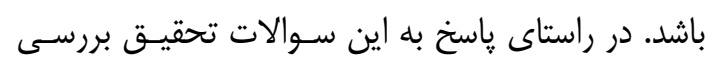

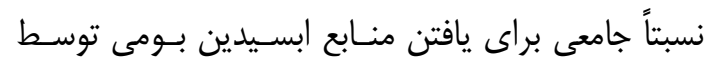

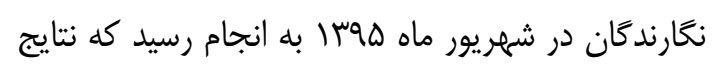

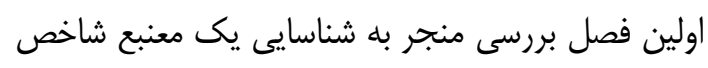

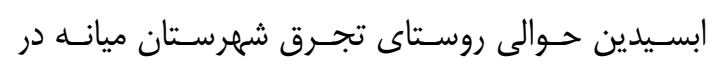

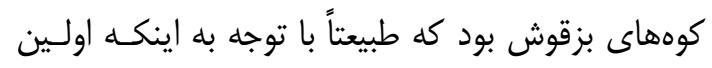

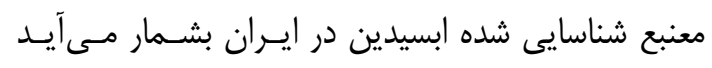

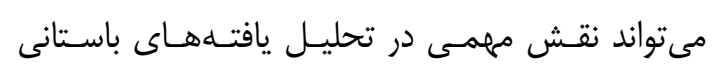
ابسيدين در اين منطقه از ايران داشته باشد.

\section{r. يِيشينه مطالعات منشأيابى ابسيدينهاى}

( ) - إ مقدمه

ابسيدين يا شيشه آتشفشـانى از ســَحهـــاى بـهـ نسـبت

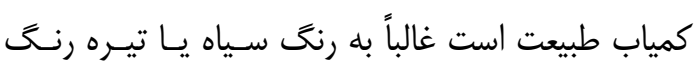

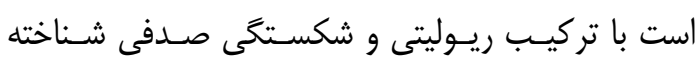
مىشـود و حاصـل انجمـاد خيلـى ســـيع (Quenching)

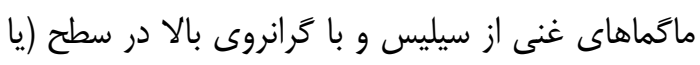

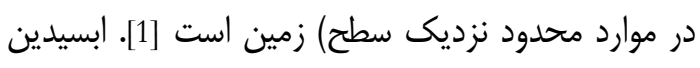

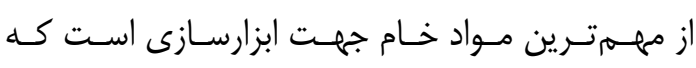

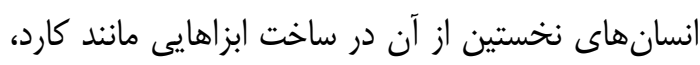

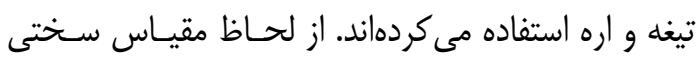

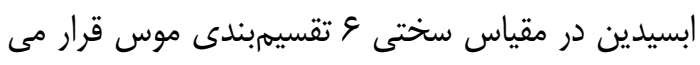

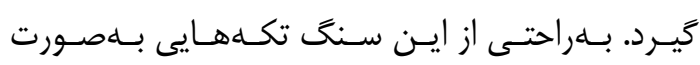
شكستخى صدفى و ورقلورقه جدا شده و لبههاى بسـيار تيزى را براى كاربردهاى مختلف ايجـاد مسىنمايسـ. بــــ

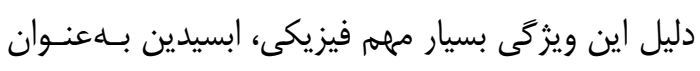

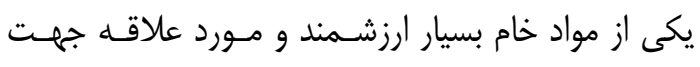

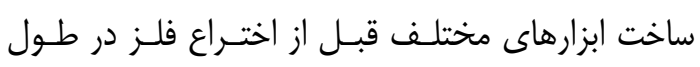

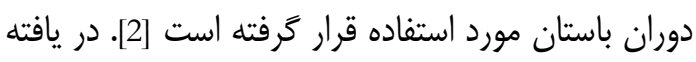

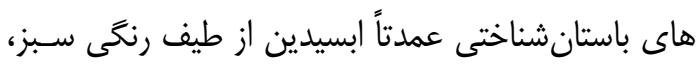

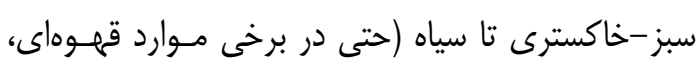

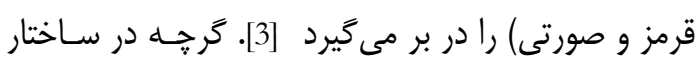

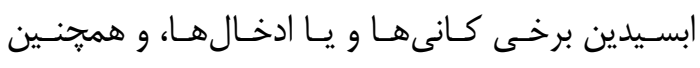

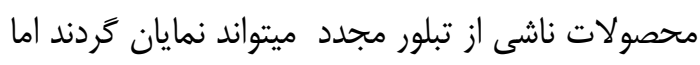

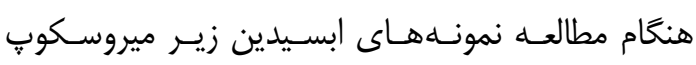

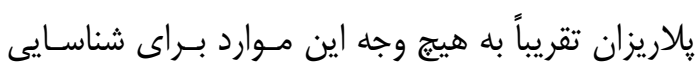

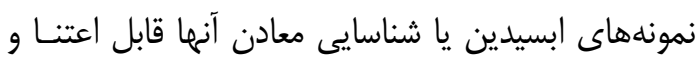
كاربردى نيست. از اين رو آناليزهاى شيميايى يكى فرآين مايند استاندارد جهت شناسايى منشا ابسـيدين مـورد اسـتفاده

$$
\text { قرار ترفته است [1]. }
$$

بطور كلى ابسيدينها بر اساس سـاختار شـيميايى و

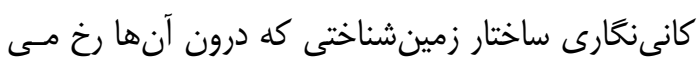

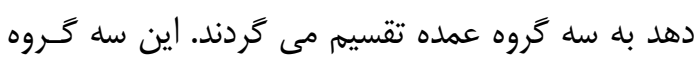

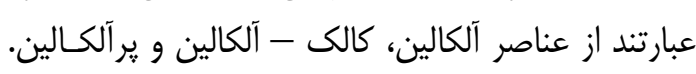

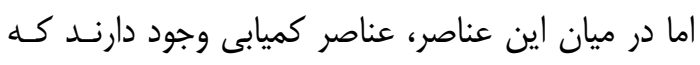

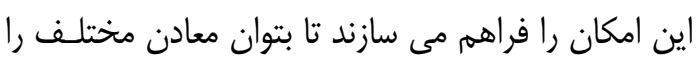

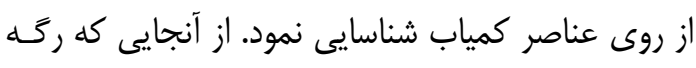

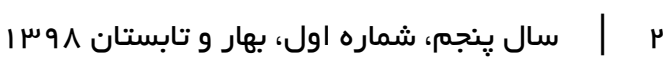


آسانتر از حاجىفيروز مى داند و اينگَونه نتيجه كيرى مسى

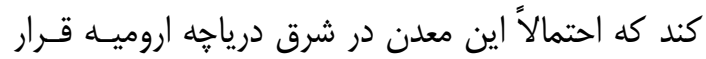

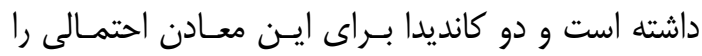
كوههاى آتشفشانى سـهند و سـبلان معرفى مسىنمايـــ

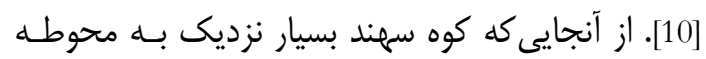

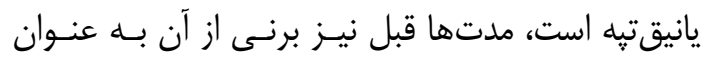

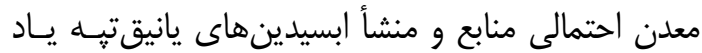

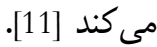
منشأيابى ابزارهاى باستانى از گرايشهـاى اساسـى

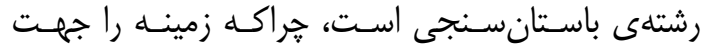
بررسى تجارتهاى بيش از تاريخ، جُخونكَى تهيـهـ مـواد

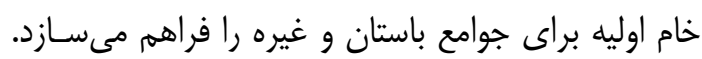

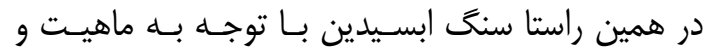

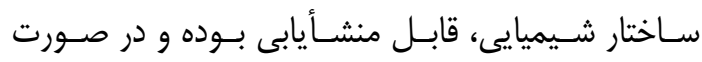

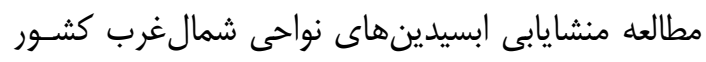

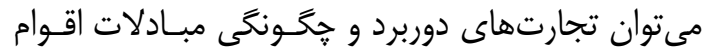

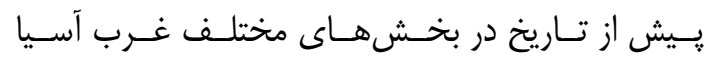

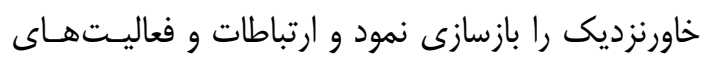

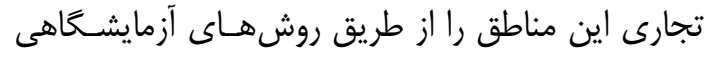

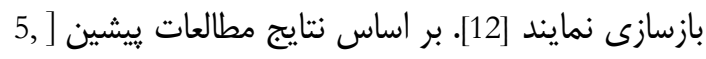

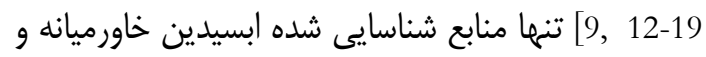

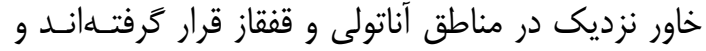

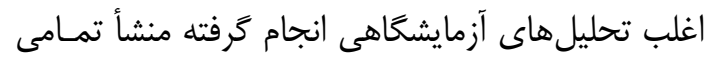

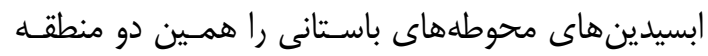

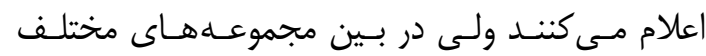

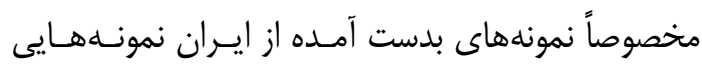

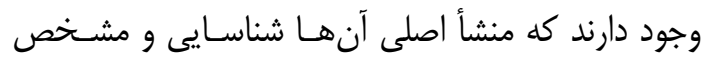

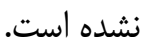

در سالهاى اخيـر متخصصـانى از ايـران سـى در

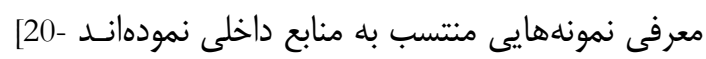
[22 كه در اغلب موارد باتوجه به اينكه هيج نمونسهاى از مناز

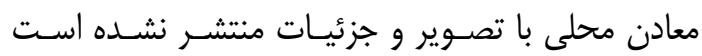
بلهورت قطع و يقين نمىتوان با استناد به اين نوشتارها

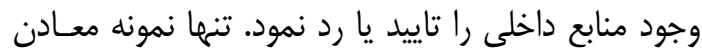

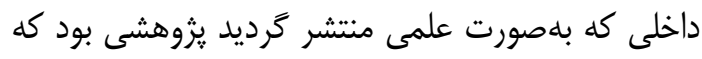

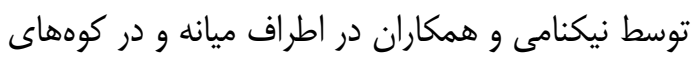

\section{شمال غرب ايران}

رنفرو و همكاران آغازَّر مطالعات ابسيدين در خاورميانـهـ

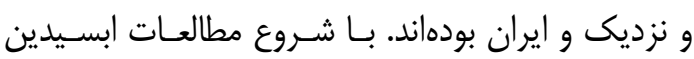

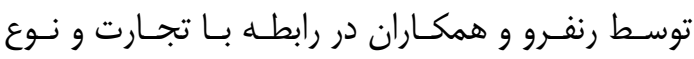

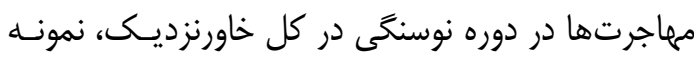

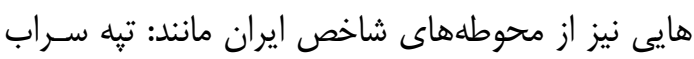

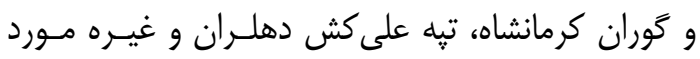

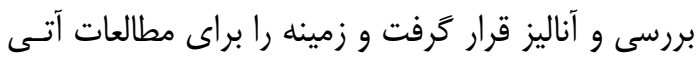

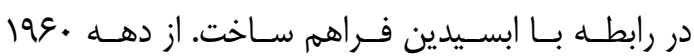
ميلادى تا دهه •19V همانند ساير مناطق خاور نزديـك

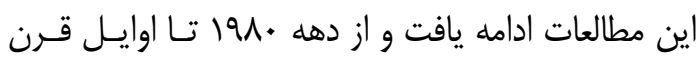

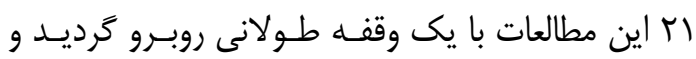

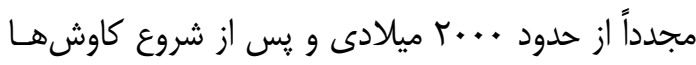

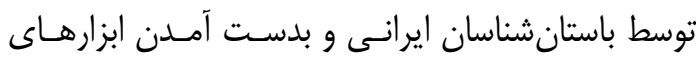

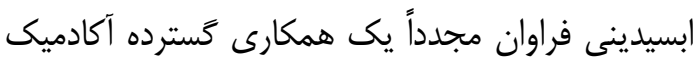

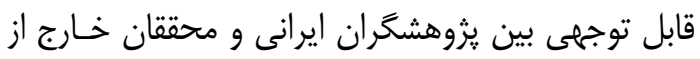

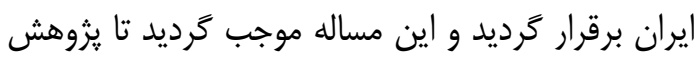
هاى علمى دوجانبهاى در اين مقطع به انجـام رسـد. در

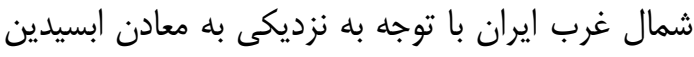

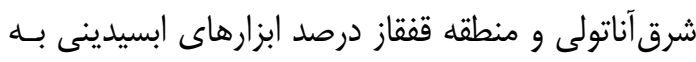
دست آمده نسبت به ساير منـاطق ايـران بسـيار بيشـتر

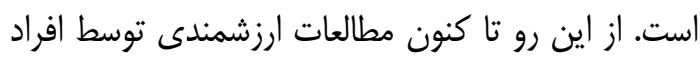

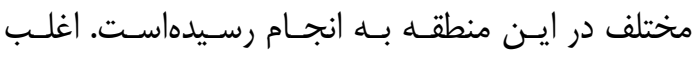

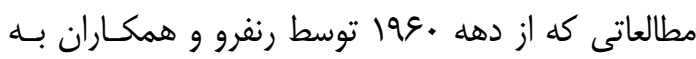

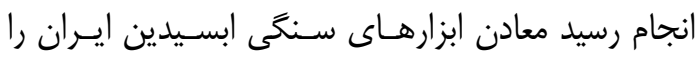

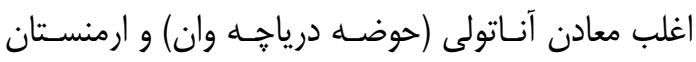

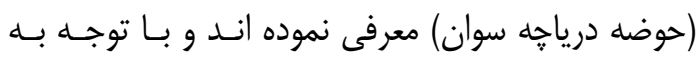
اينكه در طى بازه زمانى هزاره ششم تا سـوم ق.م. (دوره

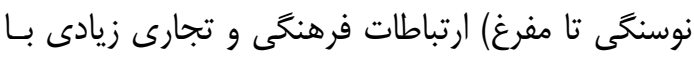

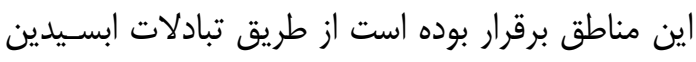

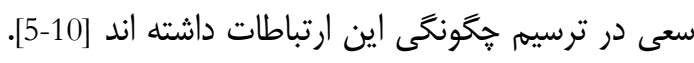

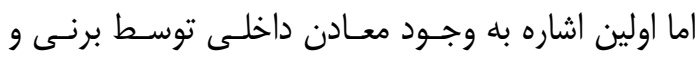

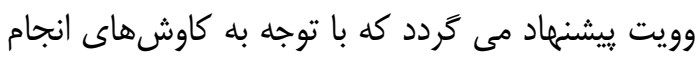

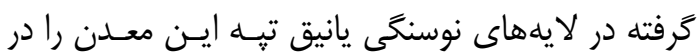

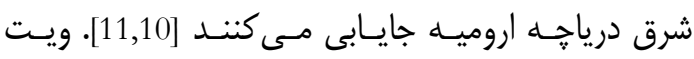
همجنين با توجه به فراوانى ابزارهاى ابسيدين يانيق تيه

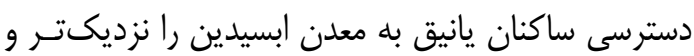



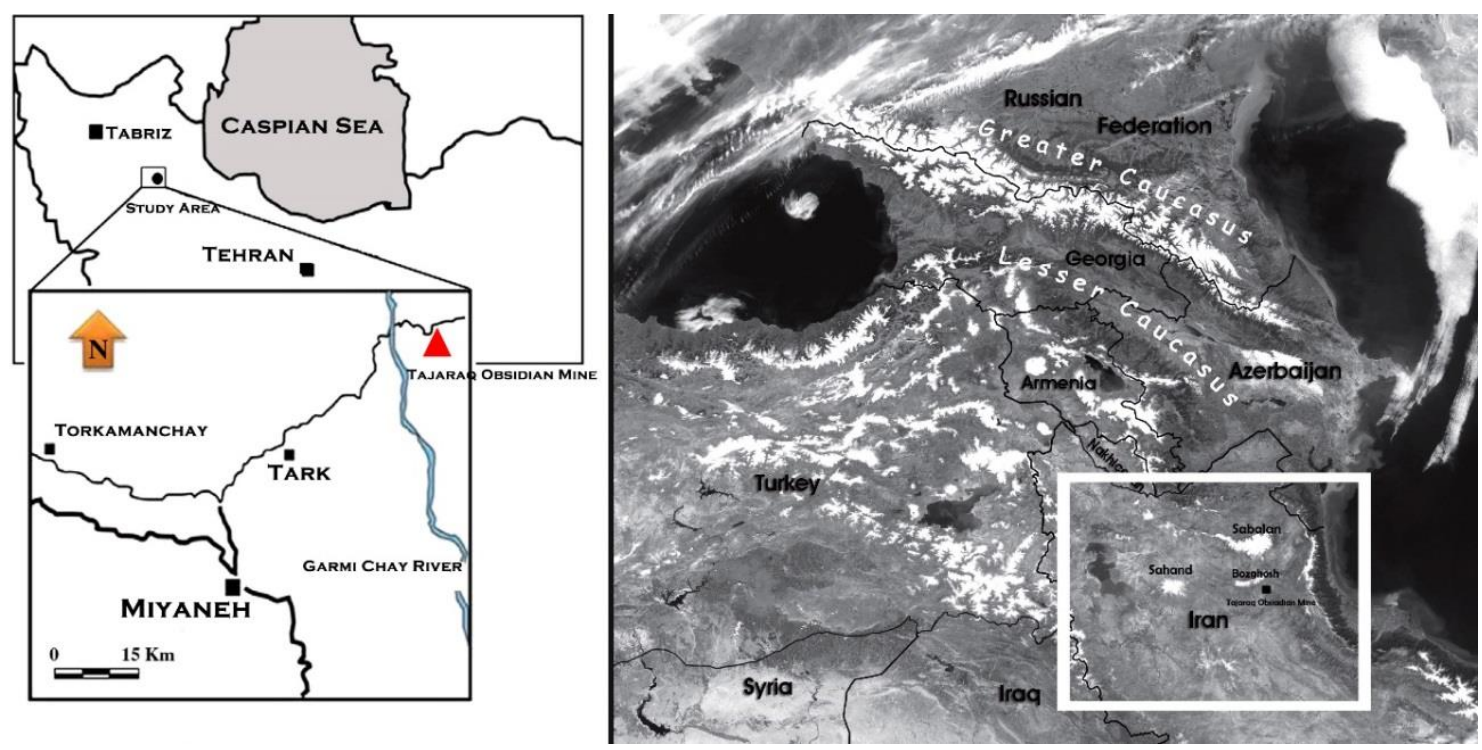

شكل (: موقعيت جغرافيايى منطقه مورد مطالعه و منبع ابسيدين تجرق ميانه در استان آذربايجان شرقى

Fig. 1: Geographical location of the study area and the Tajaraq deposit of obsidian in Miyaneh, and Ghizilja, East Azarbaijan province, NW IRAN

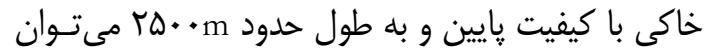

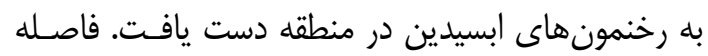

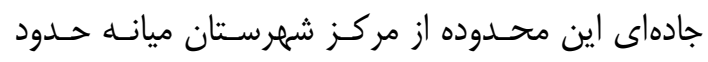

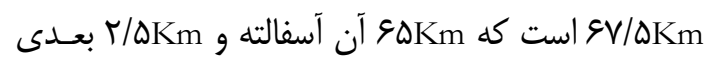

آن خاكى است (شكلهاى آو كاء).

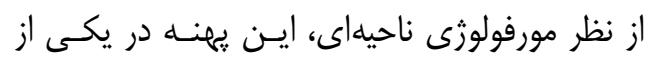

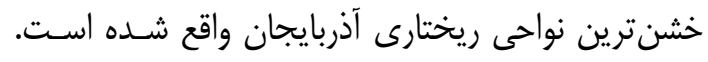

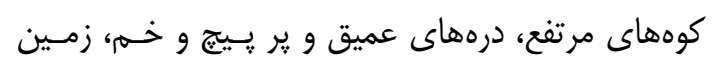

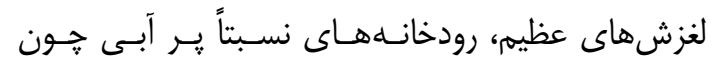

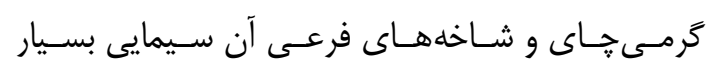

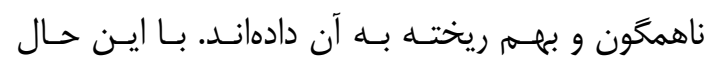

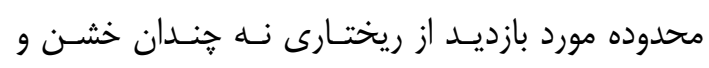

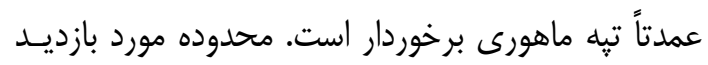

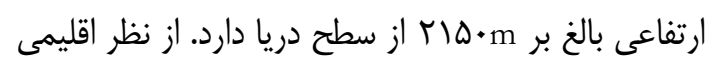

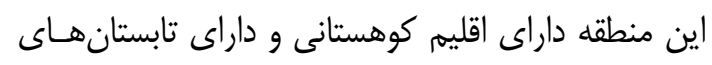

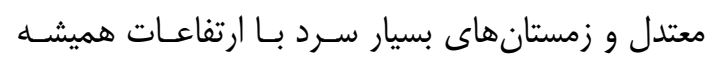

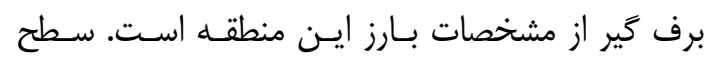

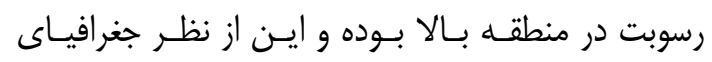

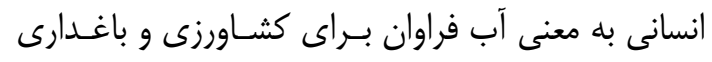

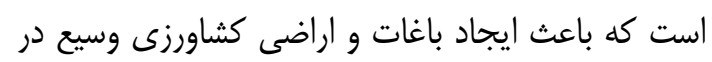

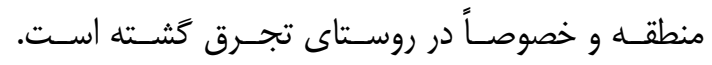

بزقوش به انجام رسيد [24-23]. امـا بـا شناسـايى منـابع جديد ابسيدين در منطقه تجرق كوههاى بزقوش ميانه و

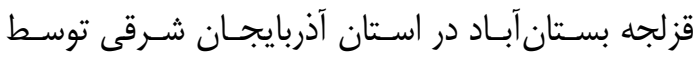

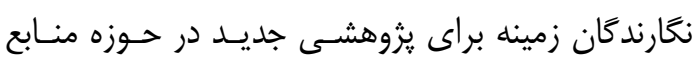

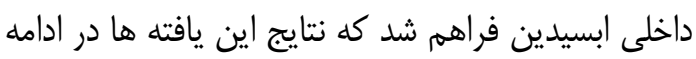
به تفصيل آمده است.

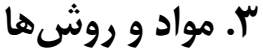

"- ا. موقعيت جغرافيايى منبع ابسيدين تجرق وقدان

\section{بزوق ميانه}

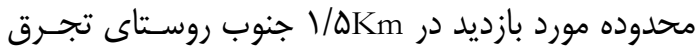

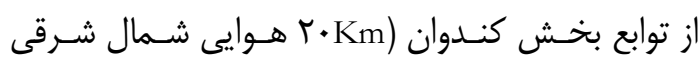

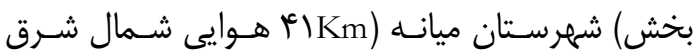

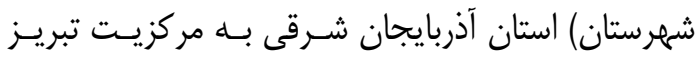

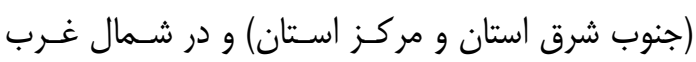

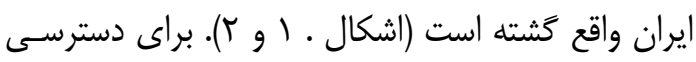

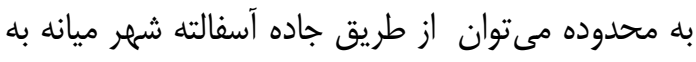

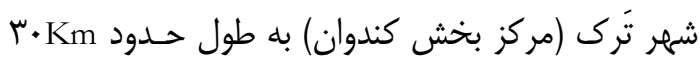

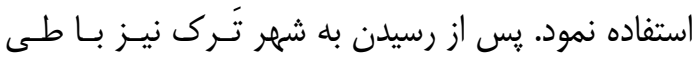

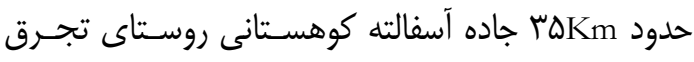
قابل دسترس است. از روستاى تجرق با استفاده از جـاده 
فورستريت و ولاستونيتدار و مقاديرى متادياباز حَزارش شده است. بر روى اين واحدها سازندهاى زمـينشناسى ولاسي

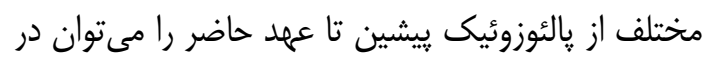

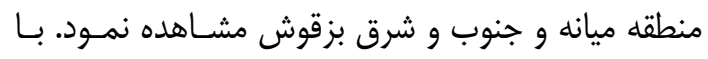

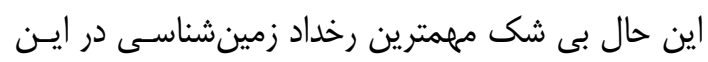

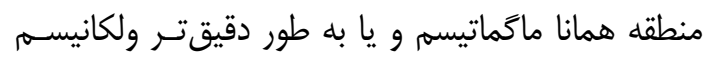

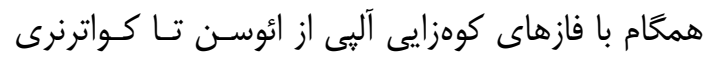

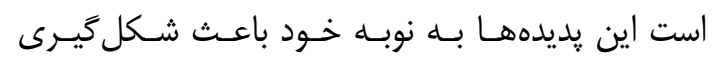

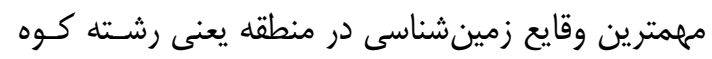

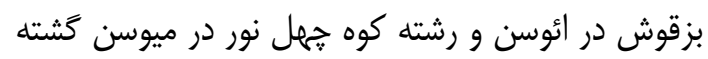

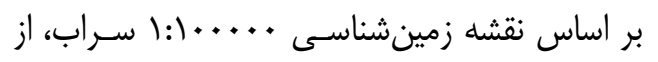
قديم به جديد (شكل r)، واحدهاى عمده رخنمون يافتـه

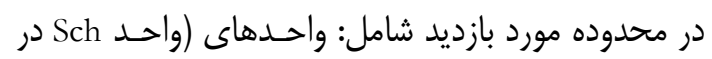

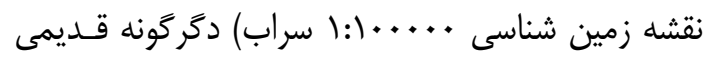
منتسب به ير كامبرين متشكل از ميكا شيست، آندالوزيت شيست و مرمر هستند. بر روى واحد شيسـتى يـاد شـــه

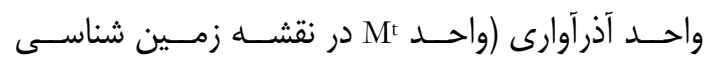
يروكالاستيكاب) (1:.....

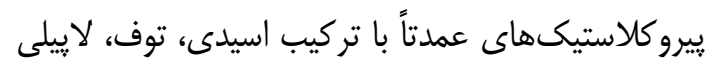

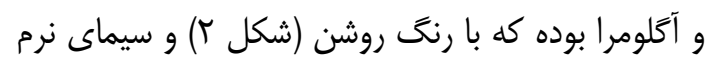

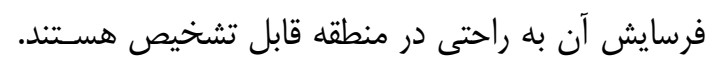

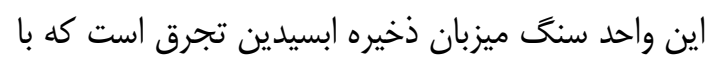

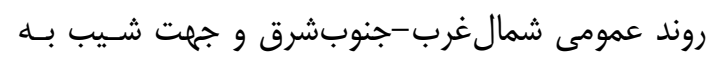

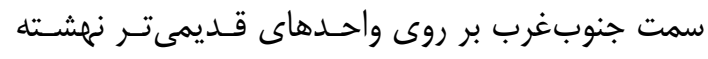

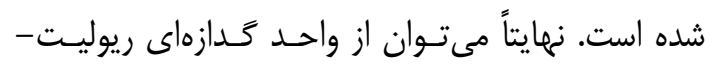

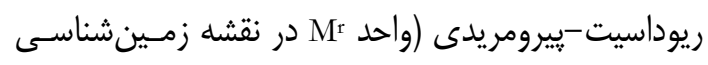

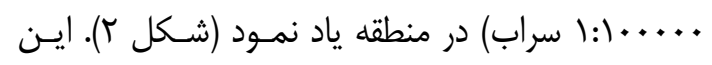

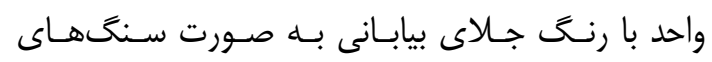

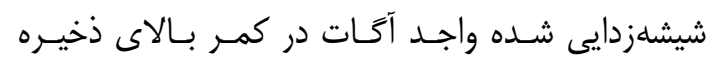
ابسيدين تجرق قرار گرفته است (شكل ؟ّ).

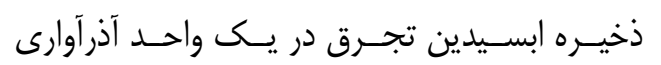

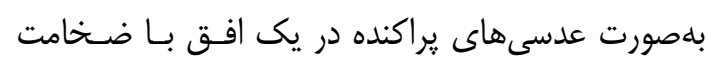

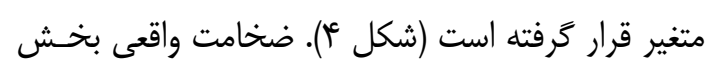

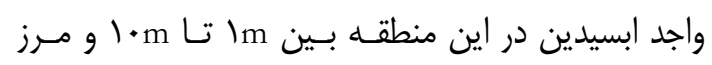

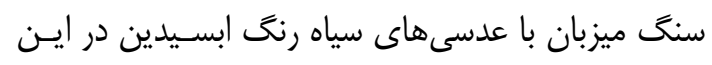
ناحيه به طور كامل مشخص است (شكل ه) و بــه نظـر

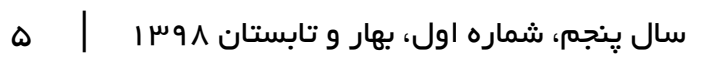

نزديكترين تجمع انسانى به اين محدوده نيـز روسـتاى

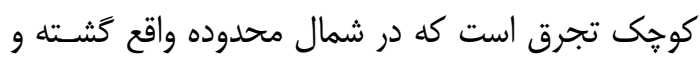

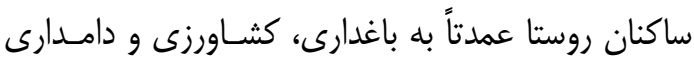

$$
\text { مشغول هستند. }
$$

\section{r-r.r. زمين شناسى منطقه مورد مطالعه}

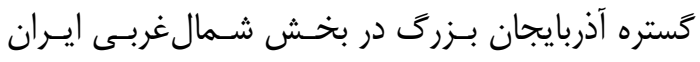

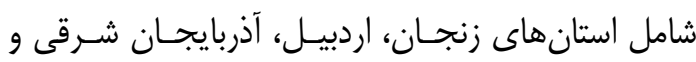

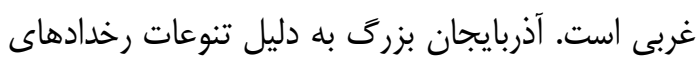

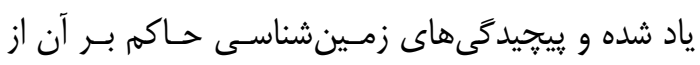

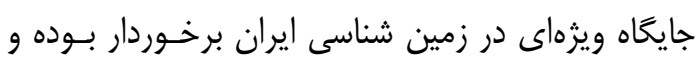

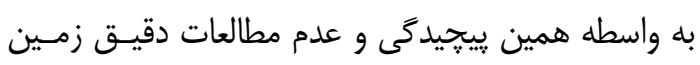

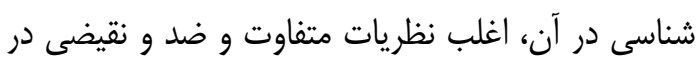

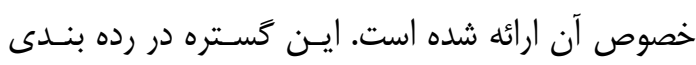

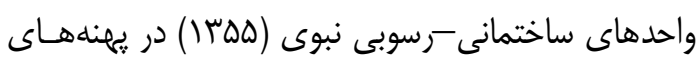

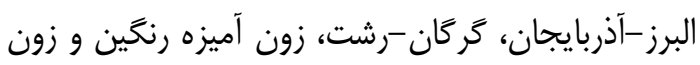

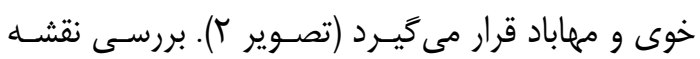

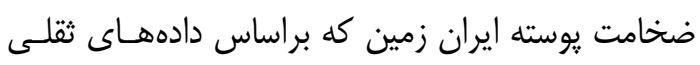

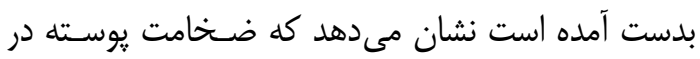

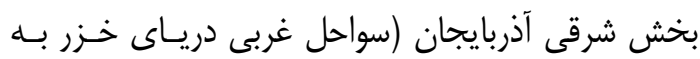

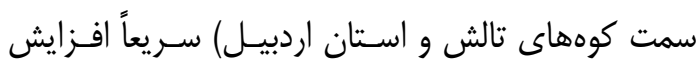

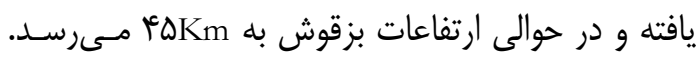

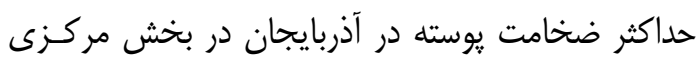

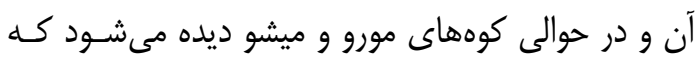

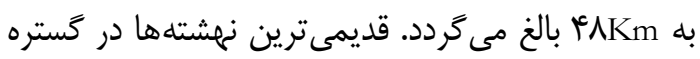

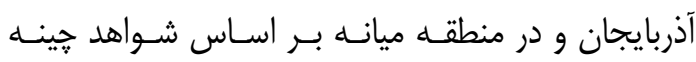
شناسى موجود منتسب به ير كامبرين مسى باشـــ كـهـ در نقاط مختلف آن و اغلب در امتداد كسلهها و مناطق بـان بـالا

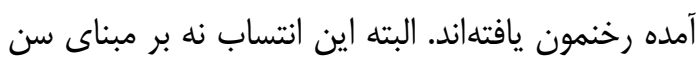

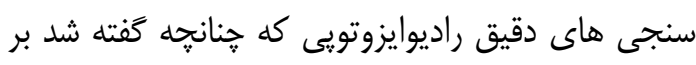

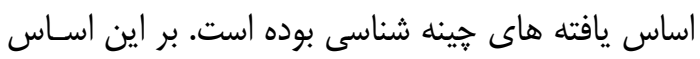

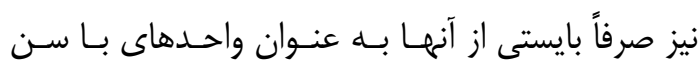

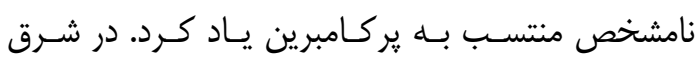

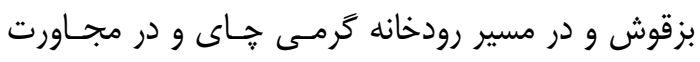
روستاى نى باغى و سارى قميش رخنمون نسبتاً وسـيعى درى دري

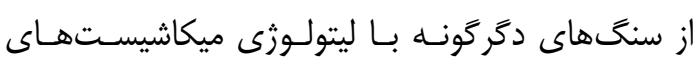

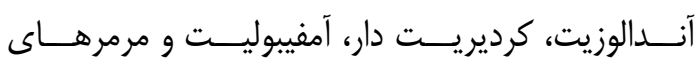




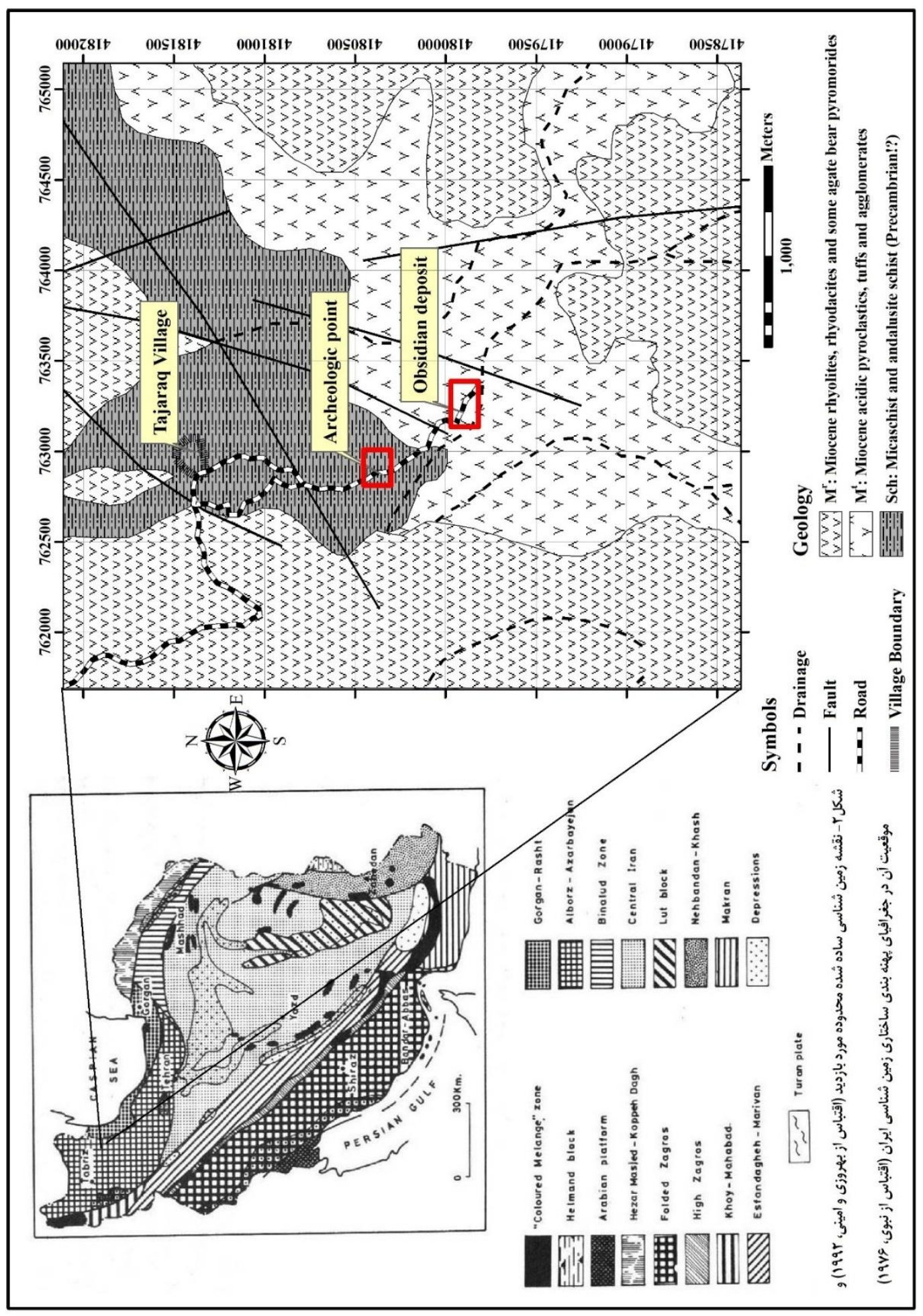

شكل r. نقشه زمين شناسى ساده شده محدوده مورد بازديد [25] و موقعيت آن در جغرافياى يهنه بندى ساختارى زمين شناسى ايران

Fig. 2: Simplified geological map of Tajaraq district and its location on the Iranian tectonic zoning map [25] 

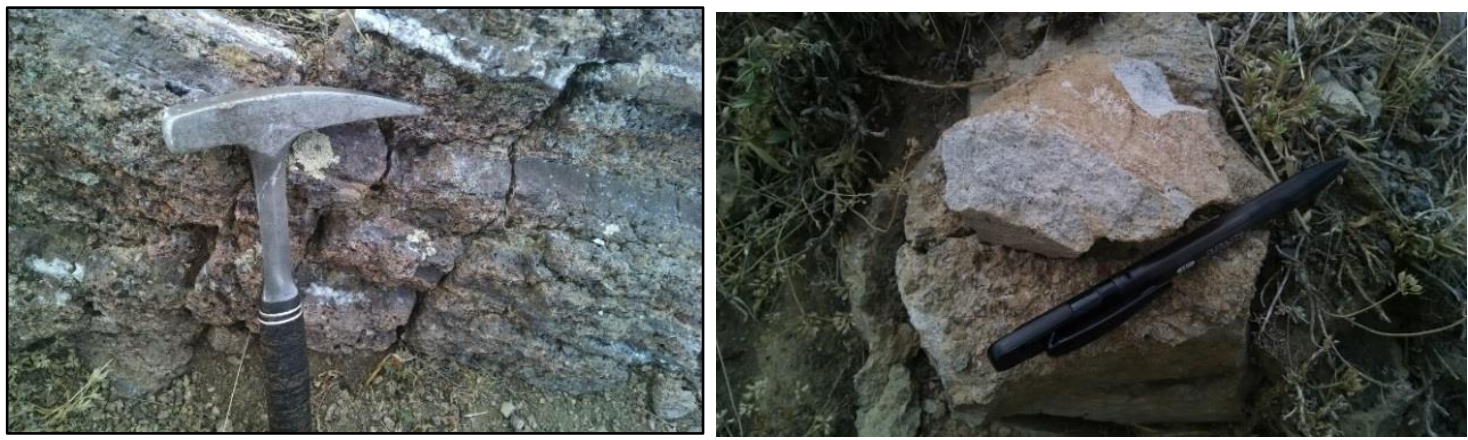

$$
\text { شكل "ّ: واحد توفى كمر پايين ذخيره ابسيدين تجرق (راست)، واحد ييرومريدى شيشه زدا شده واجد آكات در كمر بالاى ذخيره ابسيدين }
$$

تجرق (ج) (ن)

Fig. 3. Tuffic footwall of the Tajaraq obsidian leyer (right) - Devitrified pyromeridic hangingwall of the Tajaraq obsidian beds

\section{". معرفى نمونههاى مورد مطالعه}

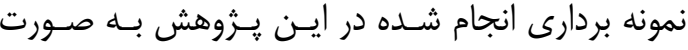

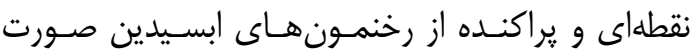

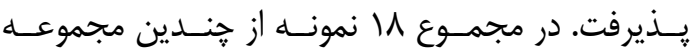

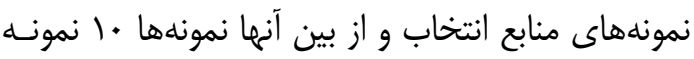

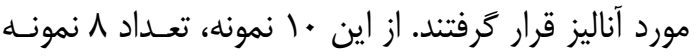
متعلق به منبع ابسيدين تجرق ميانه است و r نمونه نيـز

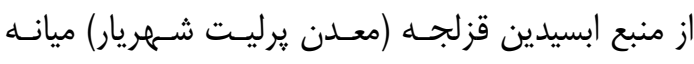

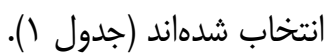

مىرسد ذخيره ياد شده ڤِ از تشكيل به كـرات توسـط

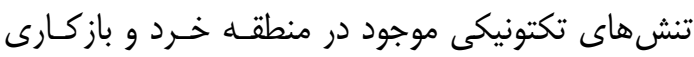
شده است (شكل 9). ابسيدينهاى موجود در اين منطقه

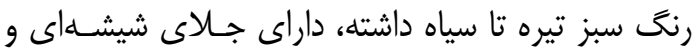

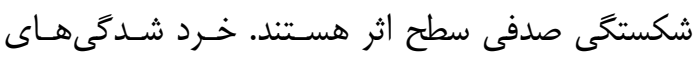

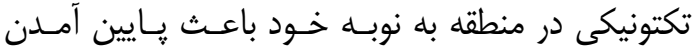

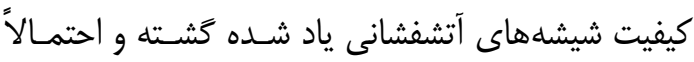

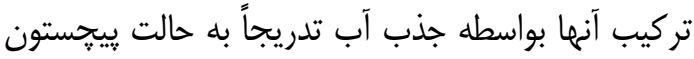

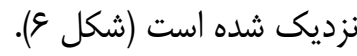

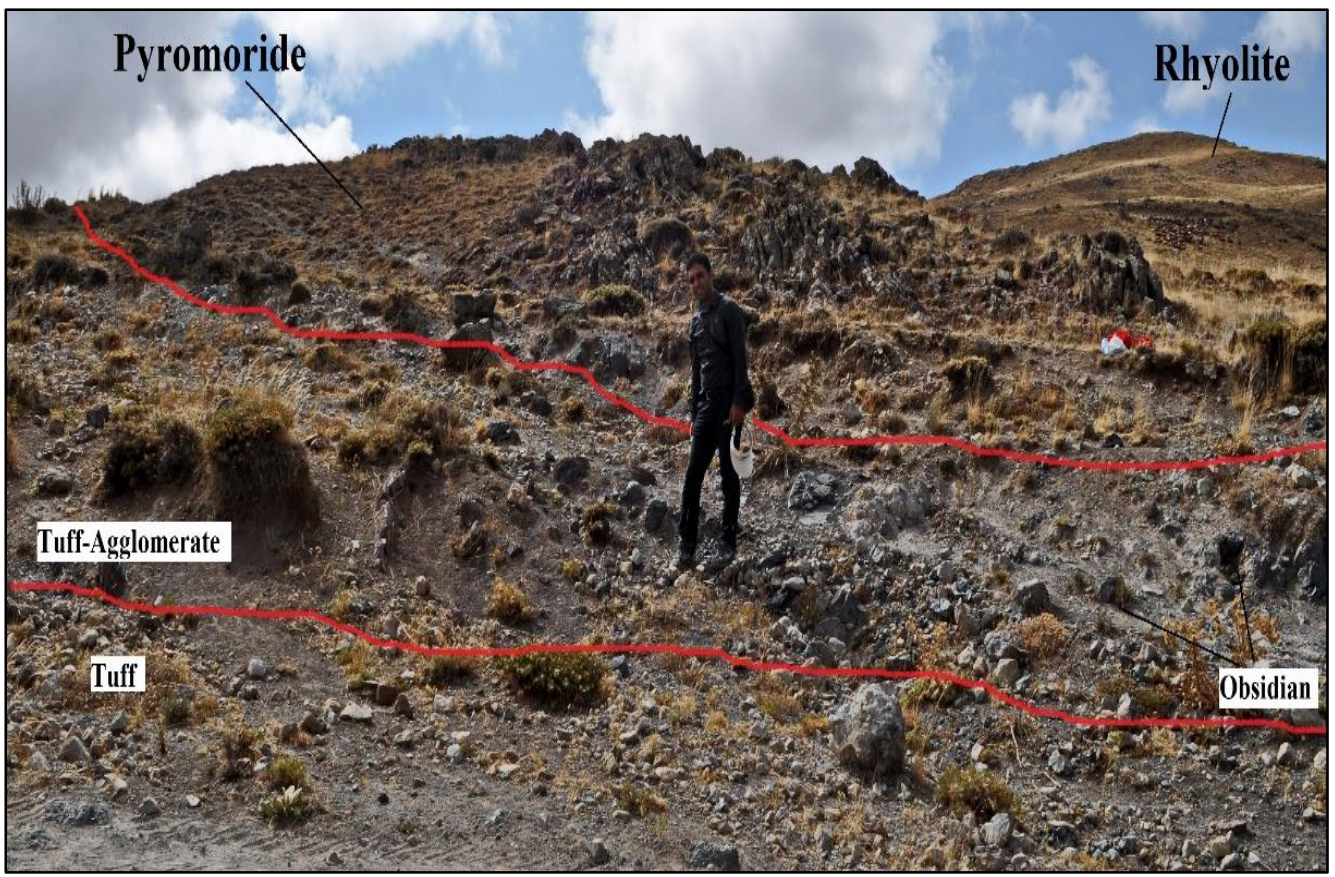

شكل عا: رخنمون واحد داراى ابسيدين و كمر بالا و كمر پايين آن (ديد به سمت جنوب)

Fig. 4: Obsidian formation outcrop and its foot and hang walls (view to South) 


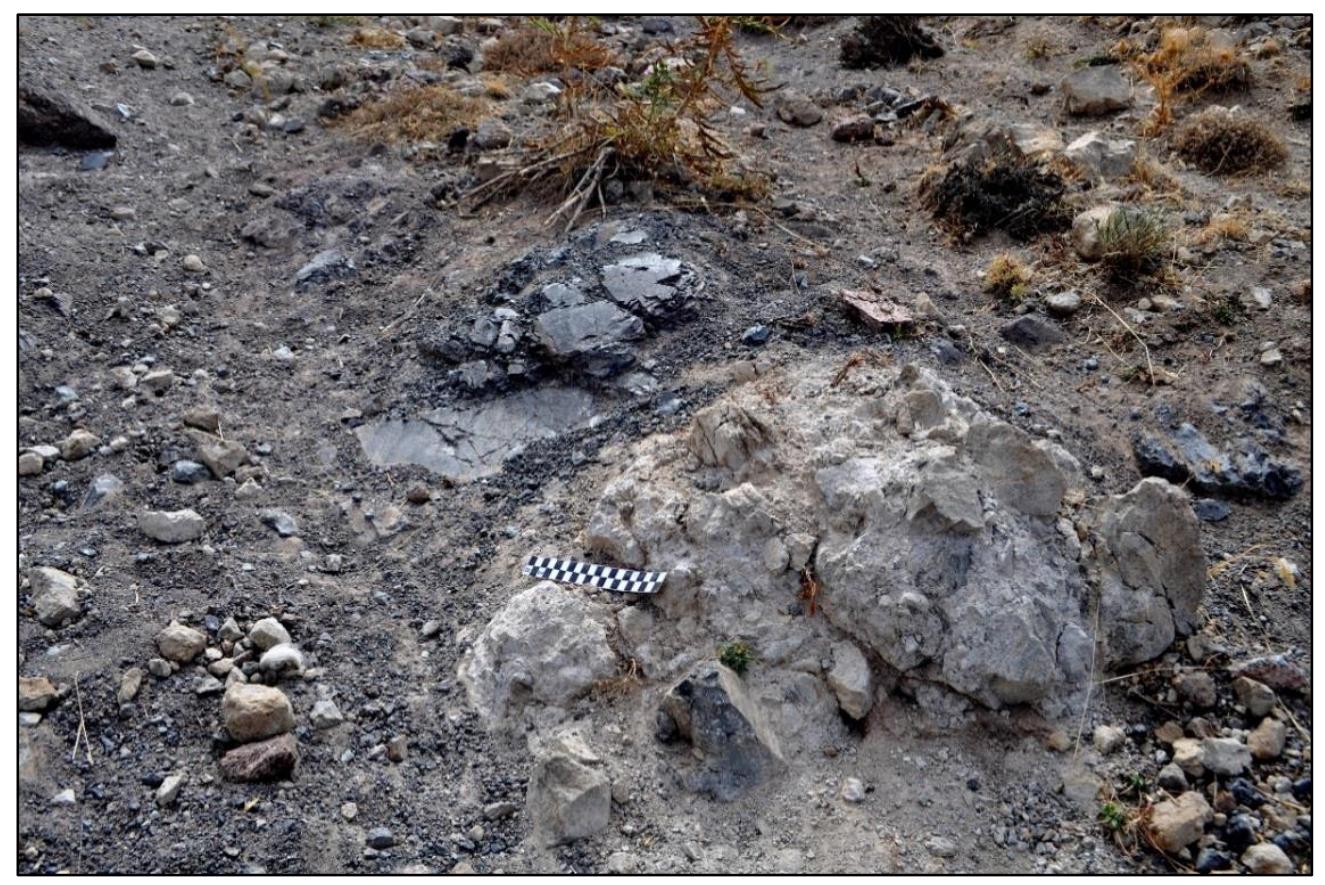

شكل ه: قرار كيرى افق ابسيدين در داخل واحد توف - آتلومر ايى (ديد به سمت جنوب)

Fig. 5: The location of Obsidian level into Tuff-Agglomerate member (view to South)

اين روش است. همجرنين بهدليل قابل حمل بودن امكان

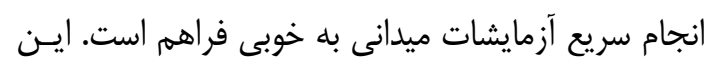

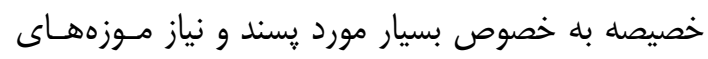

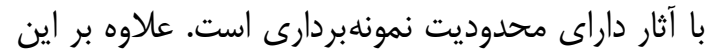

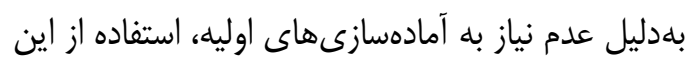

در سال هاى اخير با روى كار آمدن دسـتخاههـاى قابـل

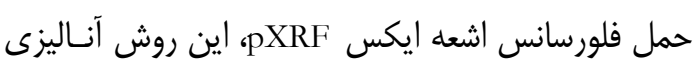

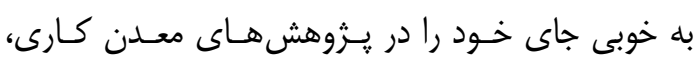

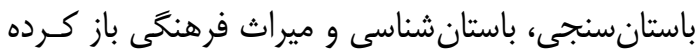
است. غيرتخريبى بودن مهمترين و شاخصترين ويزتى باسنى
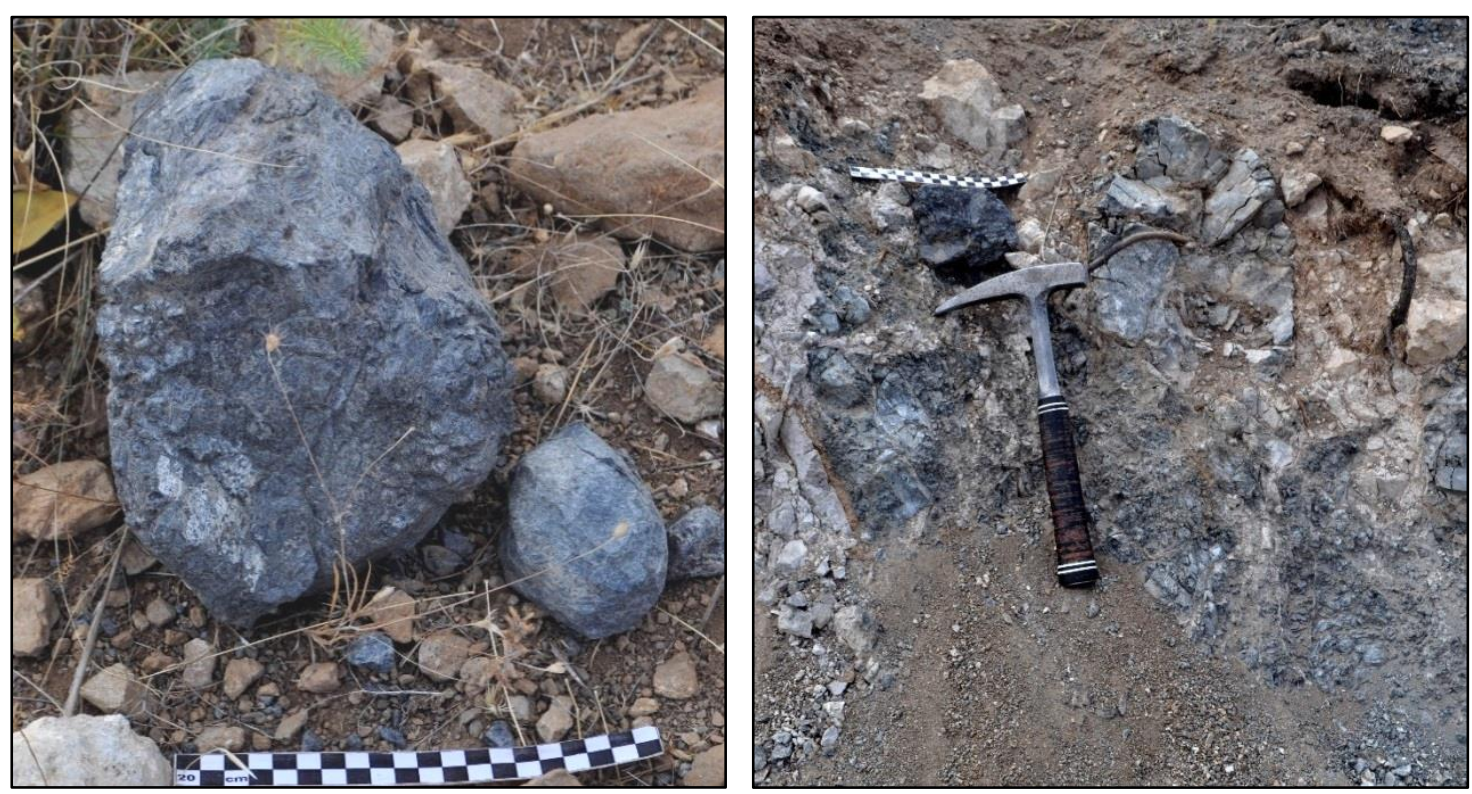

شكل ؤ نماى نزديك از از واحد خرد شده حاوى ابسيدين در تجرق (ديد به سمت جنوب)

Fig. 6: A mesoscopic view of the crushed Obsidian particles at Tajaraq (view to South) 
جدول ا: نمونههاى انتخاب شده براى آناليز از منبع ابسيدين تجرق ميانه و قزلجه بستان آباد

Table 1: Selected samples from Tajaraq, Miyeneh, and Ghizilja, Bostanabad

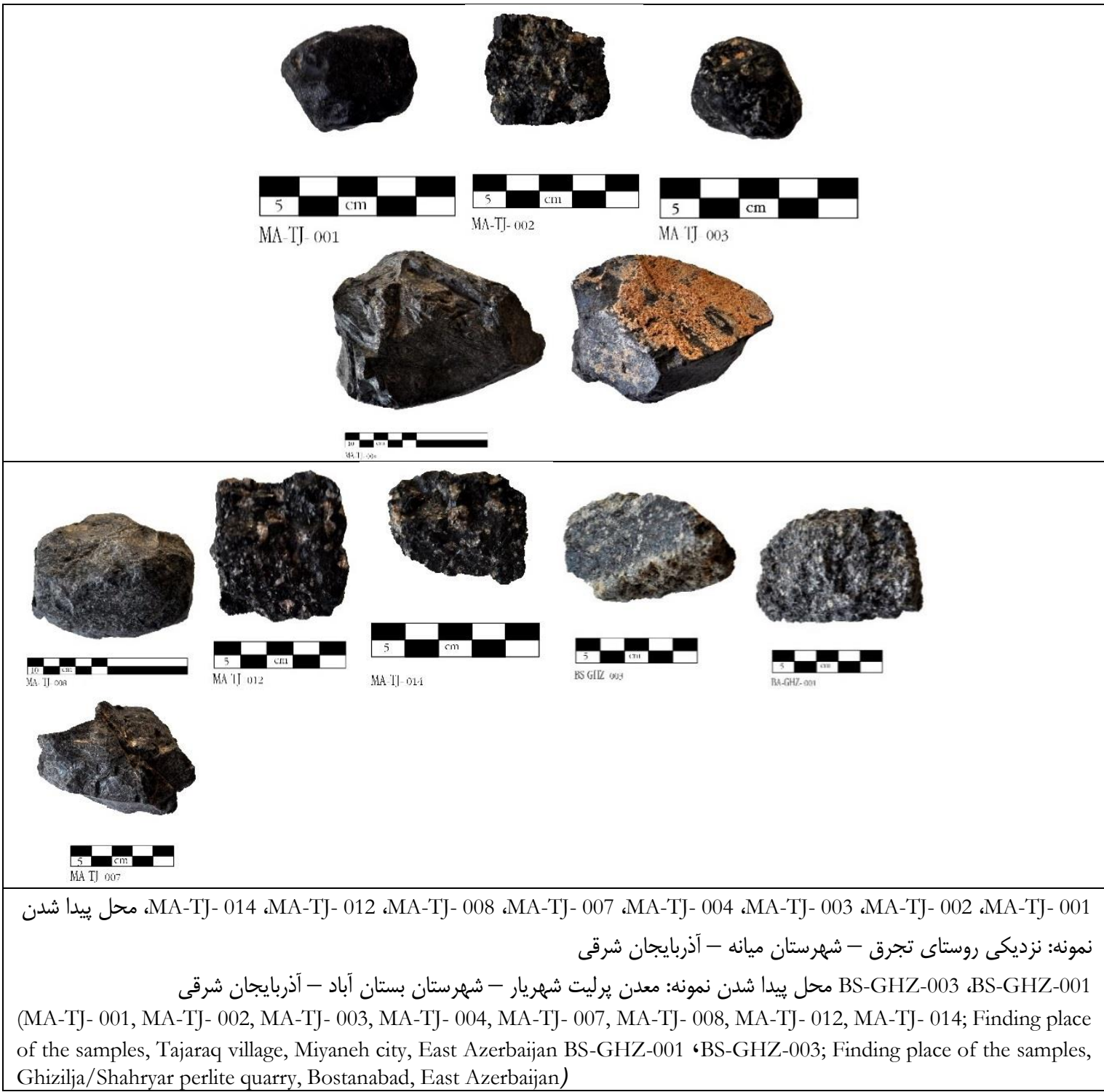

مجموع سه بار و سه نقطه متفاوت طيف سنجى صـورت

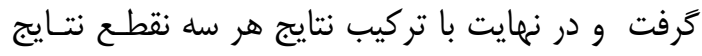

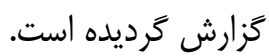

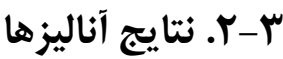

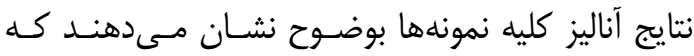

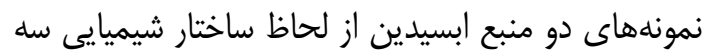

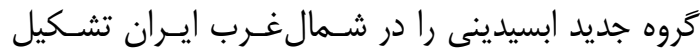

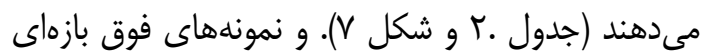

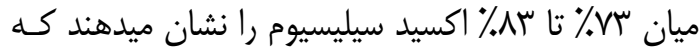

روش بلهراتب باصـرفهتـر از ديخــر روشهـاى آنـاليزى

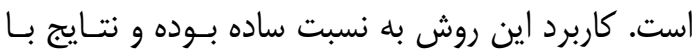

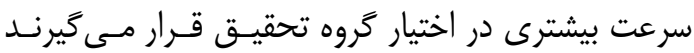

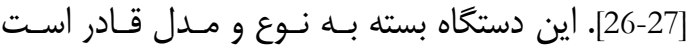

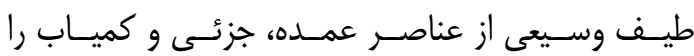

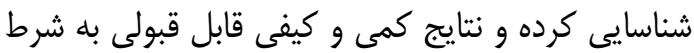

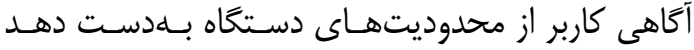
[27]. دستخاه طيفسنج فلورسانس اشعه ايكس :ريرتابـل مـورد اسـتفاده مـدل Thermo Niton XL 31 و سـاخت فلتحاه

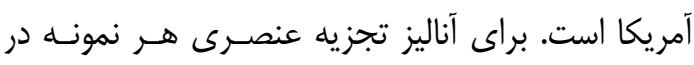


(Tajaraq Obsidian Mine

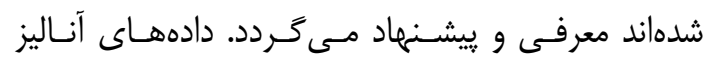

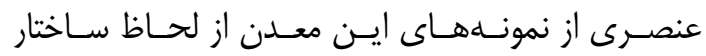

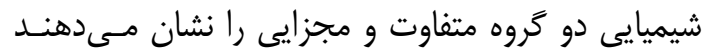

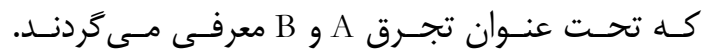

$$
\begin{aligned}
& \text { با توج به ويزگىهاى فوقالذكر همخى در رده ابسـيدين }
\end{aligned}
$$

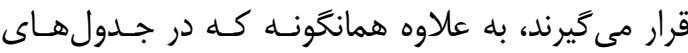

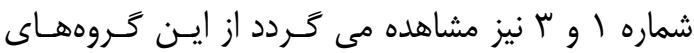

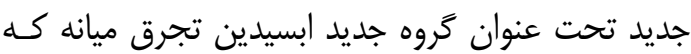

$$
\begin{aligned}
& \text { از نزديكى روسـتاى تجـرق ميانـهـ ( MA TJ -Miyaneh }
\end{aligned}
$$

جدول r: نتايج آناليز شيميايى نمونههايى از منابع ابسيدين در تجرق ميانه و منبع ابسيدين قزلجه بستان آباد (اكسيد عناصر برحسب درصد (wt\% وزنى

Table 2: pXRF results of elemental analysis of the samples from Tajaraq, Miyaneh, and Ghizilja Bosta-nabad (oxides normalized to $100 \mathrm{wt} \%$, without $\mathrm{Na} 2 \mathrm{O}$ )

\begin{tabular}{|c|c|c|c|c|c|c|c|c|c|}
\hline Samples No & Location & $\mathbf{S i O}_{2}$ & $\mathbf{T i O}_{\mathbf{2}}$ & $\mathbf{A l}_{2} \mathbf{O}_{\mathbf{3}}$ & $\mathbf{F e}_{2} \mathbf{O}_{3}$ & $\mathbf{M n O}$ & $\mathbf{M g O}$ & $\mathbf{C a O}$ & $\mathbf{K}_{\mathbf{2}} \mathbf{O}$ \\
\hline MA TJ2016-001 & NTV* & $79 / 04$ & $0 / 07$ & $13 / 25$ & $1 / 64$ & $0 / 08$ & $0 / 93$ & $0 / 46$ & $4 / 51$ \\
\hline MA TJ2016 003 & NTV & $80 / 53$ & $0 / 07$ & $12 / 63$ & $1 / 64$ & $0 / 07$ & $0 / 11$ & $0 / 43$ & $4 / 48$ \\
\hline MA TJ2016 002 & NTV & $75 / 9$ & $0 / 3$ & $14 / 04$ & $2 / 43$ & $0 / 11$ & 0 & $1 / 16$ & $6 / 01$ \\
\hline MA TJ2016 004 & NTV & $79 / 81$ & $0 / 08$ & $11 / 67$ & $1 / 7$ & $0 / 08$ & $0 / 67$ & $0 / 5$ & $5 / 45$ \\
\hline MA TJ2016 007 & NTV & $80 / 34$ & $0 / 07$ & $10 / 99$ & $1 / 72$ & $0 / 08$ & $0 / 72$ & $0 / 46$ & $5 / 59$ \\
\hline MA TJ2016 008 & NTV & $78 / 68$ & $0 / 07$ & $12 / 48$ & $1 / 73$ & $0 / 08$ & $0 / 9$ & $0 / 56$ & $5 / 45$ \\
\hline MA TJ2016 012 & NTV & $73 / 18$ & $0 / 39$ & $15 / 23$ & $2 / 84$ & $0 / 1$ & $1 / 26$ & $1 / 61$ & $5 / 36$ \\
\hline MA TJ2016 014 & NTV & $74 / 01$ & $0 / 38$ & $15 / 2$ & $2 / 86$ & $0 / 08$ & $0 / 56$ & $1 / 06$ & $5 / 8$ \\
\hline BS GHZ 2016 001 & SPM** & $82 / 7$ & $0 / 13$ & $10 / 88$ & $0 / 77$ & $0 / 06$ & $0 / 65$ & $0 / 01$ & $3 / 72$ \\
\hline BS GHZ 2016 003 & SPM** & $83 / 41$ & $0 / 14$ & $10 / 28$ & $0 / 72$ & $0 / 06$ & $0 / 29$ & $1 / 1$ & $3 / 92$ \\
\hline *NTV: NEAR TAJARAQ VILLAGE & & **SPM: SHAHRIAR PERLITE MINE & \\
\hline
\end{tabular}

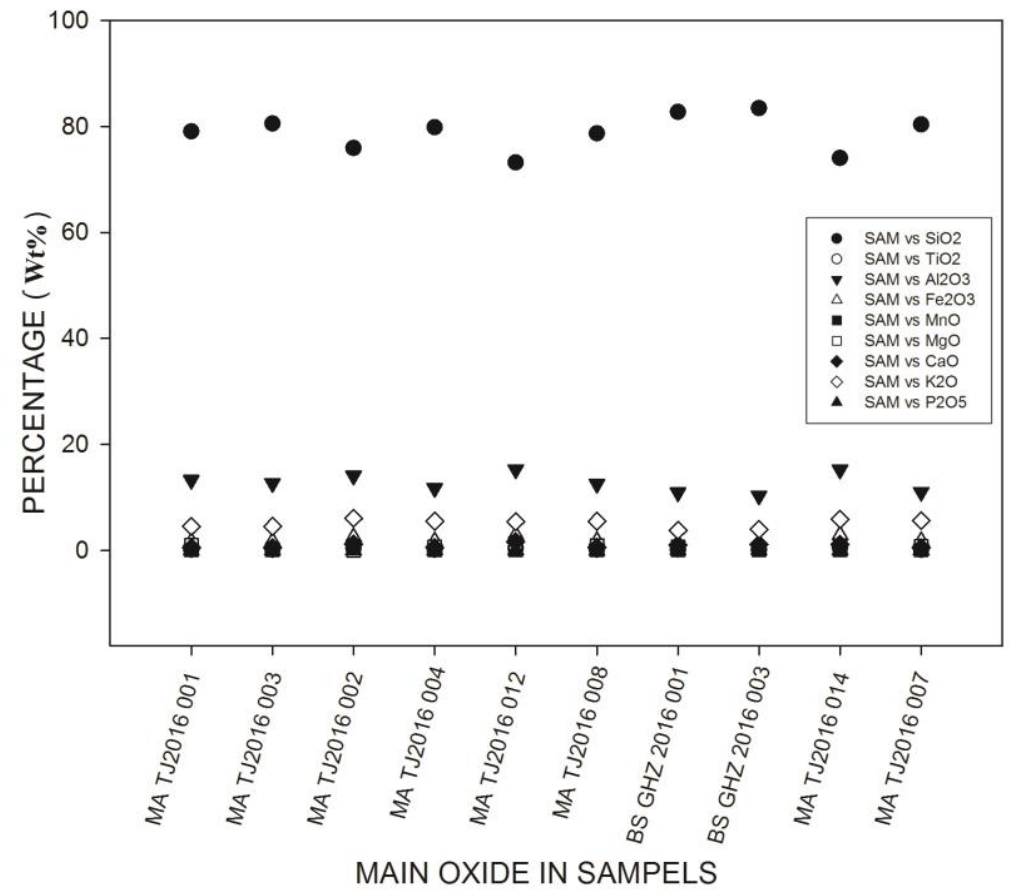

شكل V: مقادير درصد وزنى اكسيدهاى نمونهها از منابع ابسيدين تجرق ميانه و قزلجه بستان آباد

Fig. 7: Concentration of main oxide of samples from Tajaraq and Ghizilja obsidian sources

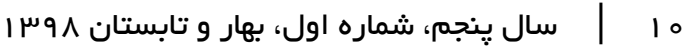


جدول "ا: نتايج آناليز شيميايى نمونهايى از منابع ابسيدين در تجرق ميانه و منبع قزلجه بستان آباد (عناصر كمياب بر حسب ppm) Table 3: pXRF results of elemental analysis of the samples from Tajaraq, Miyaneh, and Ghizilja Bostanabad (trace elements in $\mathrm{ppm}$ ).

\begin{tabular}{|c|c|c|c|c|c|c|c|c|c|c|c|}
\hline Sample No & $\begin{array}{c}\text { Loctio } \\
\mathbf{n}\end{array}$ & $\mathbf{Z n}$ & $\mathbf{A s}$ & $\mathbf{R b}$ & $\mathbf{S r}$ & $\mathbf{Y}$ & $\mathbf{Z r}$ & $\mathbf{N b}$ & $\mathbf{S n}$ & $\mathbf{S b}$ & $\mathbf{B a}$ \\
\hline MA TJ2016 001 & NTV* & $55 / 1$ & $22 / 88$ & $270 / 46$ & $2 / 79$ & $45 / 28$ & $290 / 06$ & $66 / 74$ & $7 / 62$ & $12 / 81$ & $185 / 02$ \\
\hline MA TJ2016 003 & NTV & $55 / 11$ & $23 / 95$ & $275 / 85$ & $2 / 56$ & $45 / 17$ & $295 / 62$ & $69 / 77$ & 7 & $9 / 19$ & $131 / 11$ \\
\hline MA TJ2016 002 & NTV & $48 / 62$ & $10 / 48$ & $215 / 96$ & $101 / 43$ & $35 / 54$ & $611 / 94$ & $62 / 85$ & $8 / 26$ & $13 / 91$ & $477 / 03$ \\
\hline MA TJ2016 004 & NTV & $52 / 18$ & $21 / 33$ & $257 / 28$ & $4 / 96$ & $41 / 8$ & $271 / 03$ & 62 & $7 / 65$ & $12 / 38$ & $165 / 31$ \\
\hline MA TJ2016 007 & NTV & $53 / 76$ & $20 / 57$ & $254 / 27$ & $5 / 21$ & $41 / 13$ & $266 / 19$ & $61 / 3$ & $9 / 46$ & $13 / 75$ & $188 / 76$ \\
\hline MA TJ2016 008 & NTV & $53 / 94$ & $21 / 87$ & $261 / 25$ & $4 / 94$ & $42 / 7$ & $272 / 43$ & $62 / 6$ & $8 / 18$ & $11 / 59$ & $172 / 27$ \\
\hline MA TJ2016 012 & NTV & $55 / 71$ & $10 / 35$ & $203 / 05$ & $135 / 16$ & $34 / 28$ & $627 / 04$ & $64 / 05$ & $7 / 99$ & $11 / 62$ & $388 / 11$ \\
\hline MA TJ2016 014 & NTV & $57 / 72$ & $12 / 15$ & $237 / 4$ & $74 / 82$ & $40 / 41$ & $718 / 55$ & $73 / 68$ & $7 / 43$ & $11 / 01$ & $380 / 3$ \\
\hline BS GHZ 2016 001 & SPM** & $24 / 91$ & $9 / 01$ & $92 / 99$ & $121 / 24$ & $9 / 78$ & $77 / 52$ & $12 / 96$ & $13 / 26$ & $26 / 91$ & $1126 / 75$ \\
\hline BS GHZ 2016 003 & SPM** & $26 / 16$ & $8 / 59$ & $124 / 49$ & $126 / 26$ & $10 / 93$ & $77 / 29$ & $13 / 05$ & $11 / 46$ & $22 / 97$ & $1109 / 49$ \\
\hline *NTV: NEAR TAJARAQ VILLAGE & & \multicolumn{7}{|c}{$* *$ SPM: SHAHRIAR PERLITE MINE } & & \\
\hline
\end{tabular}

كيفيت و قابليت ساخت ابزار از بقيه نمونهها بارزتر اسـت

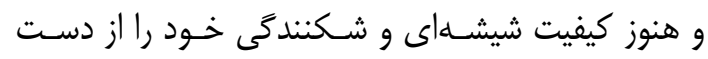

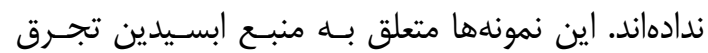

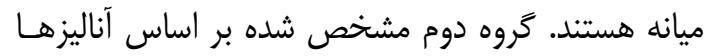

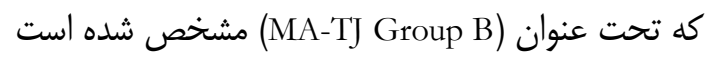
نيز كروه دوم ابسيدينهاى منبع تجرق ميانه است كه از

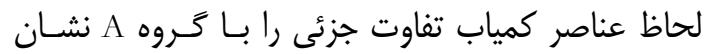

\section{ץ-ץ-1. تحليل نمودار يراكندَّى -زير كونيم

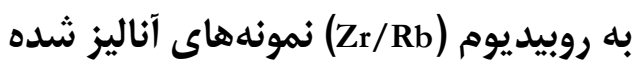

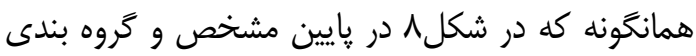

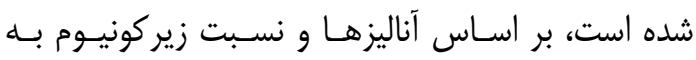
روبيدوم نمونهها سه گروه قابل تمييز است. گروهى كـهـ

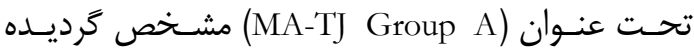

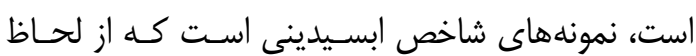

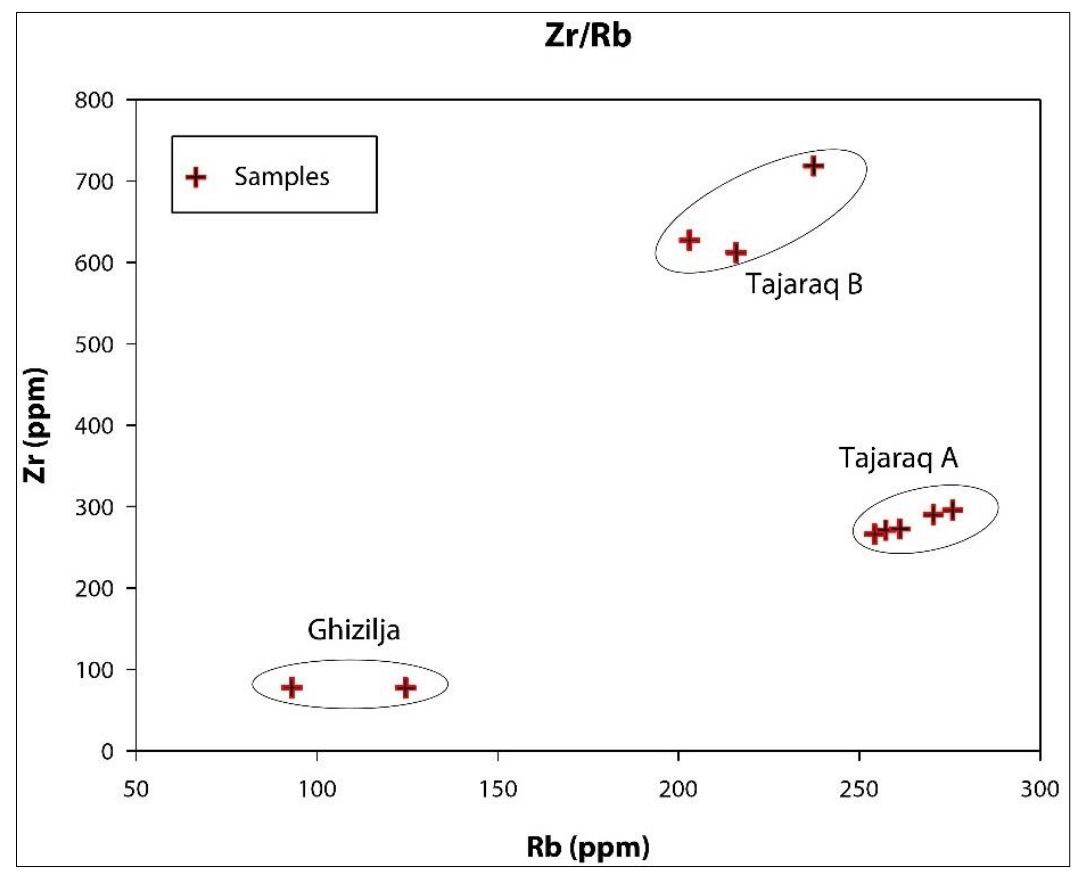

شكل م: نمودار تراكندگى زير كونيوم به روبيديوم Zr/Rb) نمونهاى آناليز شده

Fig. 8: Scatterplot of Zr versus Rb for obsidian samples from Tajaraq and Ghizilja obsidian sources (pXRF) 


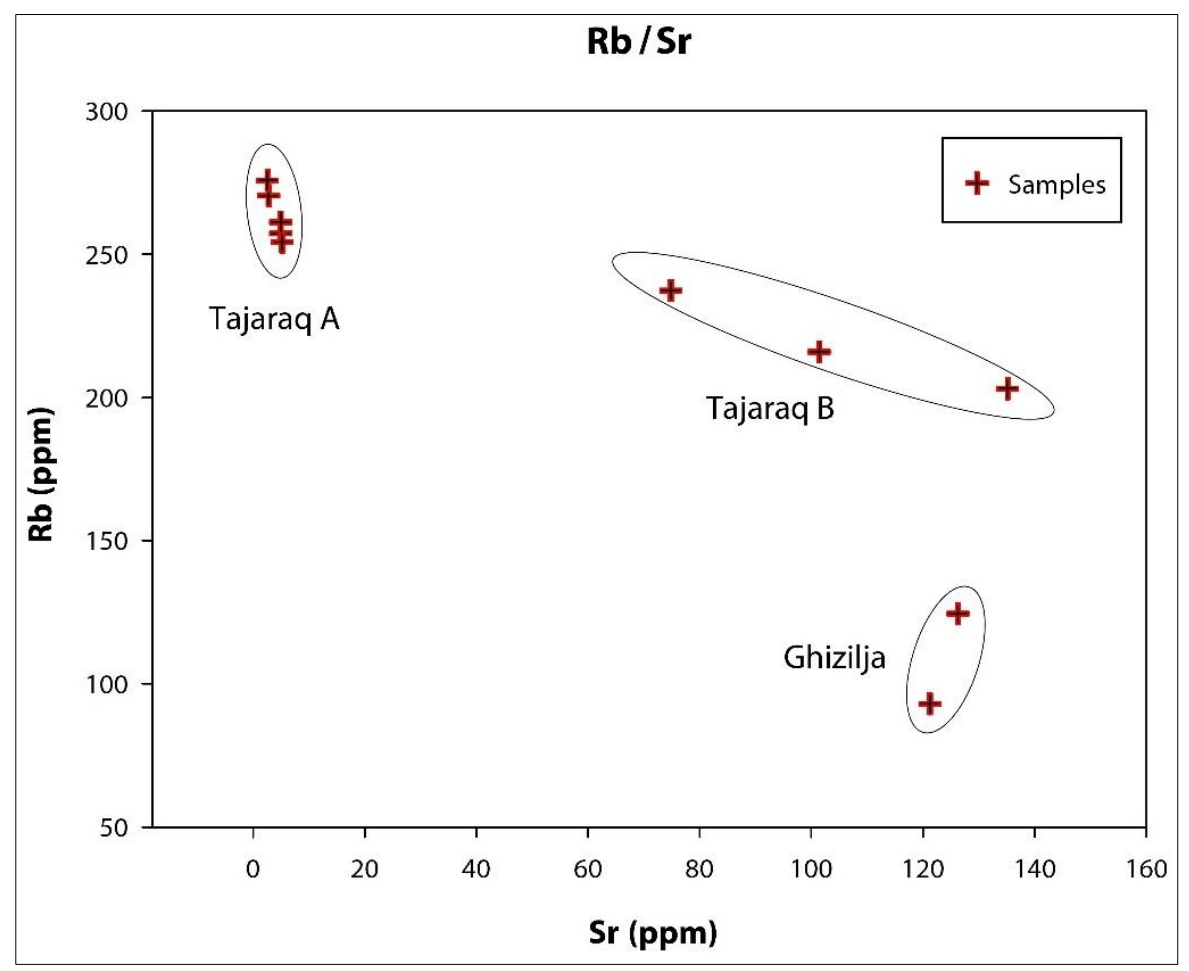

شكل ج: نمودار براكندگى استرانسيوم به روبيديوم (Sr/Rb) نمونههاى آناليز شده

Fig. 9: Scatterplot of Rb versus Sr for obsidian samples from Tajaraq and Ghizilja obsidian sources (pXRF)

همبستخى بالا با يكديخر در يك گروه قرار گرفتهاند.

\section{ه. نتيجلكيرى و بحث}

سنگ ابسيدين به مثابه كَونهاى سنگ افزار باستانى مورد

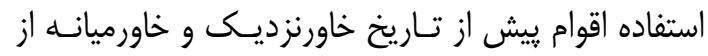

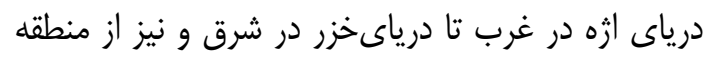

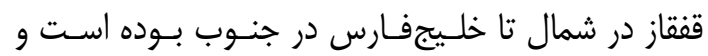

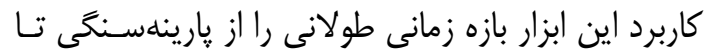

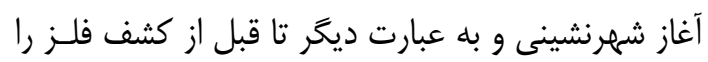
در بر مى گيرد. بنا بـر مطالعـات صـورت كرفتـهـ موجـود ابسيدين بلهعنوان يكى از فراوانترين ابزارها

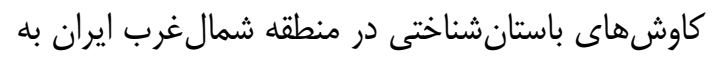
دست مى آيد. منطقه شمال غرب ايران بدليل همجــوارى

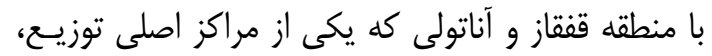

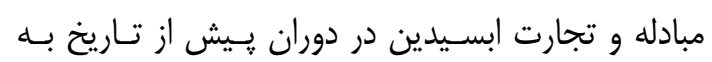
شمار مى آيد در اين جرخه مبادلاتى سهيم بـوده و آثار

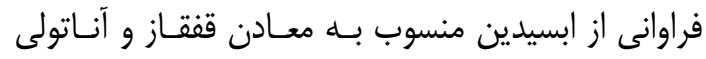

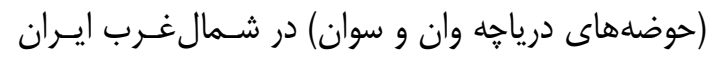

مى دهند. دو نمونه ديخر مشخص شده متعلق بــه معسدن

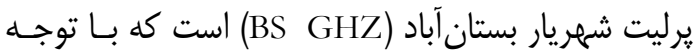
به همبستخى بالا با يكديگر در يك گروه قرار گرفته اند.

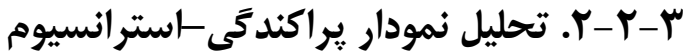 به روبيديوم (Sr/Rb) نمونه هاى آناليز شده}

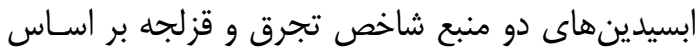

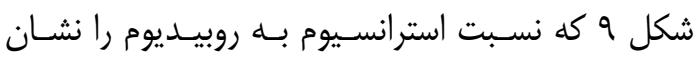
مىدهد نيز سه كروه مجزا را به نمايش مى كذارند. كروه اول متعلق به منبع ابسيدين تجرق ميانه كه تحت عندوان مشـخص ترديــــ اسـت، همـان (MA-TJ Group A) نمونههاى ابسيدينى با كيفيت و قابليت ساخت ابزار بـالا

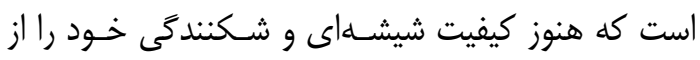
دست ندادهاند. گروه دوم تحت عنوان ( MA-TJ Group

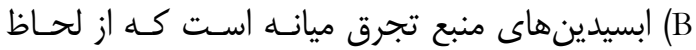
عناصر كمياب تفاوت جزئى را با كروه A نشان مى دهندئ

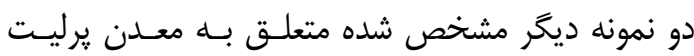
شهريار بستان آبـاد (BS GHZ) اسـت كـهـ بـا توجـهـ بـــهـ 
داشتهاند و مىتوانند به عنوان كانديداهاى استخراج منابع

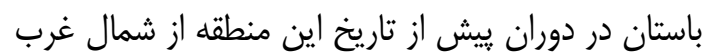

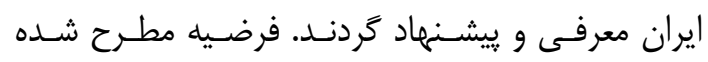

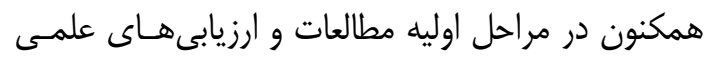

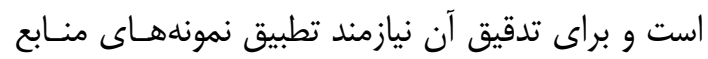

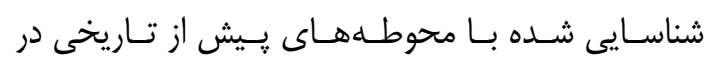

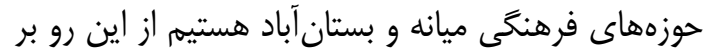

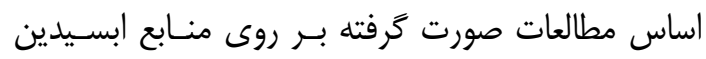

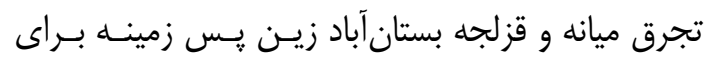

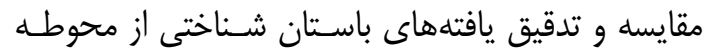

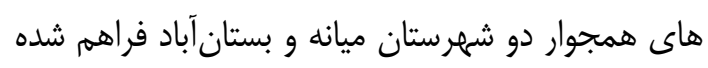
است و مىبايست جهت بررسى استفاده و يا عدم استفاده

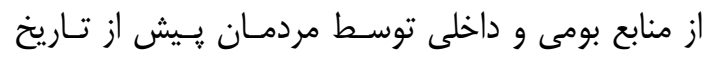

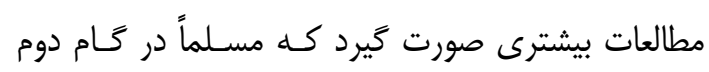
يزوهش حاضر اين مهم صورت خواهد يذيرفت.

\section{ييشنهادات و مسير ييش رو}

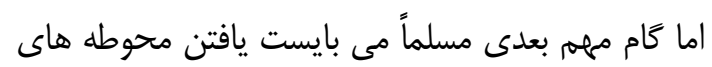

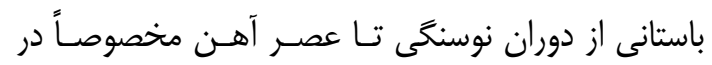

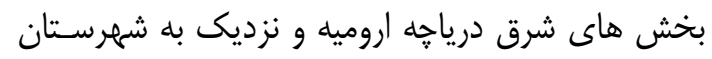

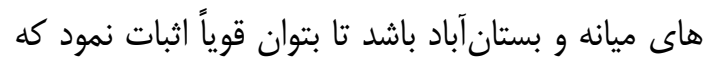

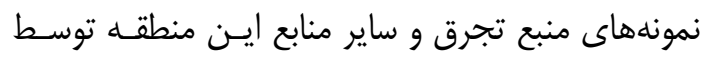

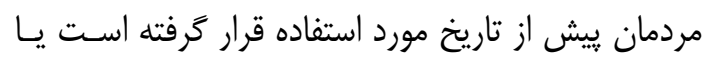

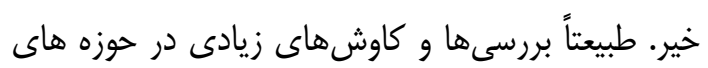

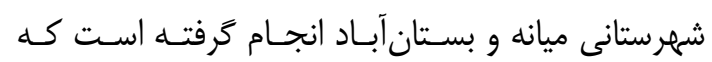

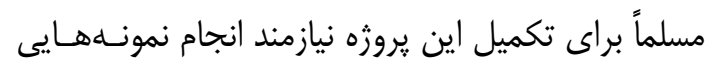
از ابسيدين هاى بدست آمده از اين محوطه ها هسـتيه.

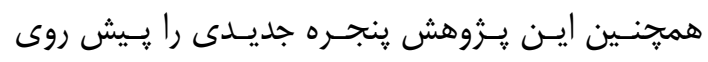

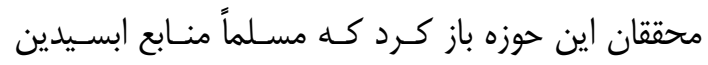

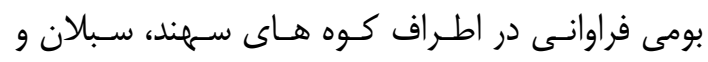

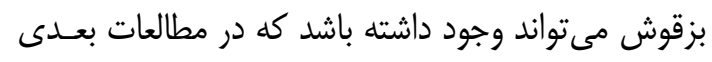

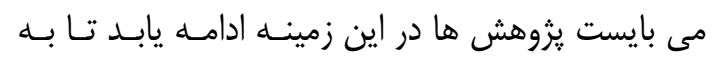

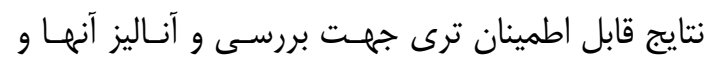
سبس تدقيق آنها با نمونه هاى باستانى را داشته باشئه.

\section{سياسگزارى}

مقاله حاضر بخشى از نتايج طرح تحقيقاتى البررسى و

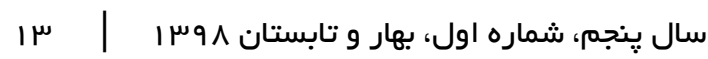

منشأيابى گرديده است. يزوهش حاضر سعى در معرفى

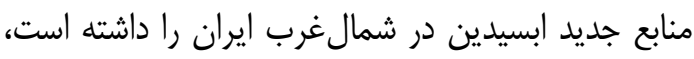

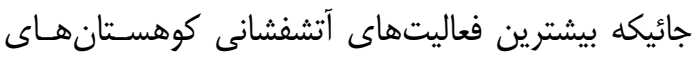
كشور در آن صورت يذيرفته است و با كوههاى معـروف سهند و سبلان جزء كانديـداهاى اصـلى بـراى اسـتفاده

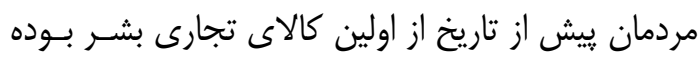

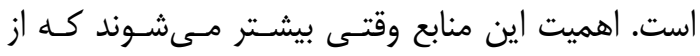

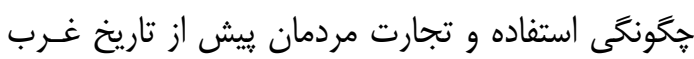

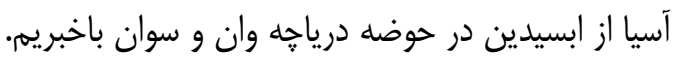

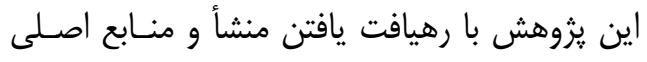

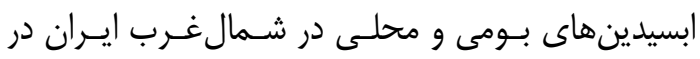

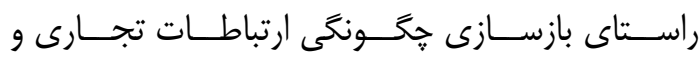

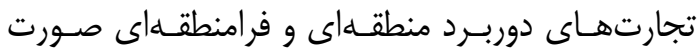

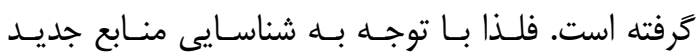

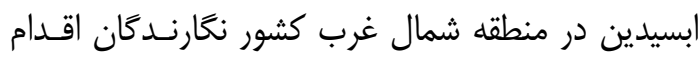

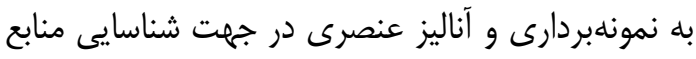

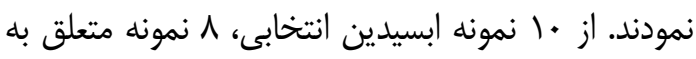

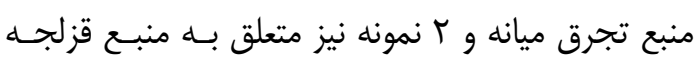

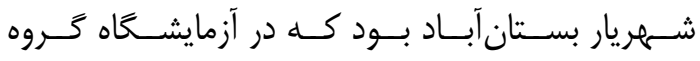

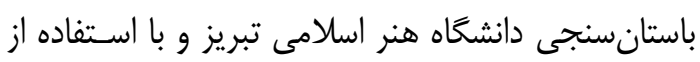

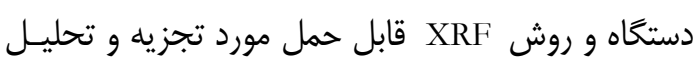

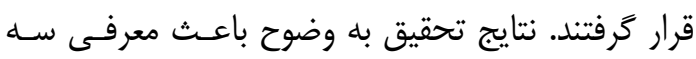

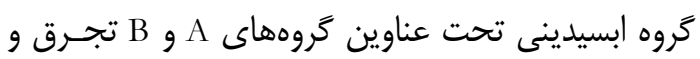

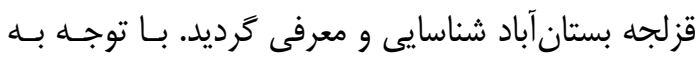

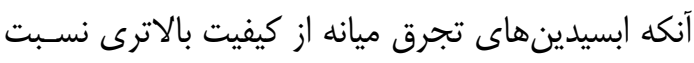
به ابسيدينهاى معدن يرليت قزلجه شهريار بسـتان آبـاد

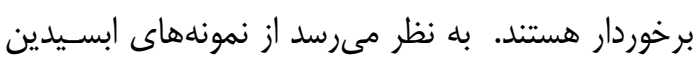

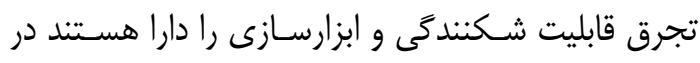

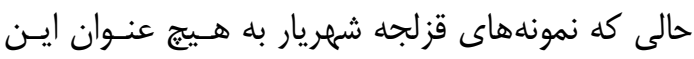

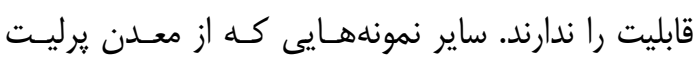

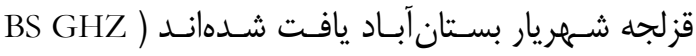
(Gizilja Perlite Mine

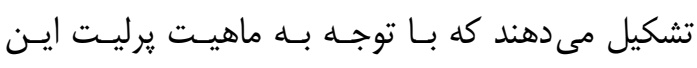

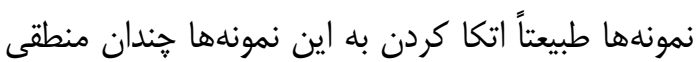

$$
\text { به نظر نمىرسند. }
$$

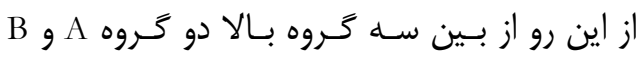

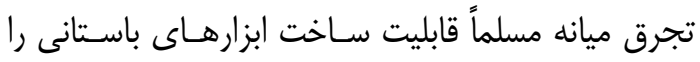




$$
\begin{aligned}
& \text { اسلامى تبريز به پايان رسيده است. از اين رو نويسندكان } \\
& \text { از اين موسسه جهت در اختيار نهادن شرايط و تأمين } \\
& \text { مالى اين يثوهش سياسگزارى مىنمايند. }
\end{aligned}
$$

\section{References}

[1] Reedy CL. Thin-section petrography of stone and ceramic cultural materials. London: Archetype; 2008.

[2] Abdi K. Obsidian in Iran from the Epipalaeolithic period to the Bronze Age. Persiens antike Pracht. 2004:148-53.

[3] Gourgaud, A. (1998). Géologie de L'obsidienne. In L'obsidienne au Proche et MoyenOrient: Du Volcan à l'Outil, In Cauvin, M. C., Gourgaud, A., Gratauze, B., Arnaud, N., Poupeau, G., Poidevin, J. L. and Chataigner, C. (Eds.). British Archaeological Reports; 1998. 15-29.

[4] Glascock MD, Braswell GE, Cobean RH. A systematic approach to obsidian source characterization. InArchaeological obsidian studies 1998 (pp. 15-65). Springer, Boston, MA.

[5] Renfrew C, Dixon JE, Cann JR. Obsidian and early cultural contact in the Near East. InProceedings of the Prehistoric Society 1966 Dec (Vol. 32, pp. 30-72). Cambridge University Press.

[6] Wright GA. Obsidian analyses and prehistoric Near Eastern trade: 7500 to 3500 BC Anthropological Papers. Museum of anthropology, University of Michigan. 1969; 37.

[7] Renfrew C. The later obsidian of Deh Luran-the evidence of Chagha Sefid. Studies in the Archaeological History of the Deh Luran Plain. 1977:289-311.

[8] Mahdavi A, Bovington C. Neutron activation analysis of some obsidian samples from geological and archaeological sites. Iran. 1972 Jan 1: 14851.

[9] Renfrew C, Dixon J. Obsidian in western Asia: a review. Problems in economic and social archaeology. 1976:137-50.

[10] Voigt, M. M. Excavation at Neolithic Gritille. Anatolica 1988. XV: 215-232.

[11] Burney CA. The excavations at Yanik Tepe, Azerbaijan, 1962: third preliminary report. Iraq. 1964; 26(1):54-61.

[12] Chataigner C, Poidevin JL, Arnaud NO.

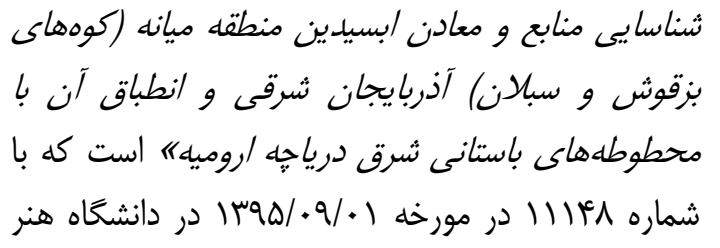

Turkish occurrences of obsidian and use by prehistoric peoples in the Near East from 14,000 to 6000 BP. Journal of Volcanology and Geothermal Research. 1998 Oct 1;85(1-4):517-37.

[13] Renfrew C, Dixon JE, Cann JR. Further analysis of Near Eastern obsidians. InProceedings of the Prehistoric Society 1969 Feb (Vol. 34, pp. 319-331). Cambridge University Press.

[14] Dixon, J., Cann, J. and Renfrew, C. Obsidian and the Origins of Trade. Scientific American. 1968 218(3): 38-46.

[15] Cann JR, Dixon JE, Renfrew C. Obsidian analysis and the obsidian trade. InScience in archaeology. A survey of progress and research 1969 (pp. 578-591).

[16] Durrani SA, Khan HA, Taj M, Renfrew C. Obsidian source identification by fission track analysis. Nature. 1971 Sep; 233(5317):242.

[17] Dixon JE. Obsidian characterization studies in the Mediterranean and Near East. Advances in obsidian glass studies: archaeological and geochemical perspectives. 1976:288-333.

[18] Blackman MJ. Provenance studies of Middle Eastem obsidian from sites in highland Iran. InArchaeological chemistry-III 1984 Jan 1 (pp. 19-50).

[19] Frahm EE. The Bronze-Age obsidian industry at Tell Mozan (ancient Urkesh), Syria: redeveloping electron microprobe analysis for 21 st-century sourcing research and the implications for obsidian use and exchange in northern Mesopotamia after the Neolithic. University of Minnesota; 2010.

[20] Khademi Nadooshan F, Philips SC, Safari M. WDXRF spectroscopy of obsidian tools in the northwest of Iran. International Association for Obsidian Studies Bulletin. 2007; 37:3-6.

[21] Ghorabi S, Glascock MD, Khademi F, Rezaie A, Feizkhah M. A geochemical investigation of obsidian artifacts from sites in northwestern Iran. IAOS Bulletin. 2008; 39:710.

[22] Nadooshan FK, Ayvatwand M, Deghanifar H, Glascock MD, Colby Phillips S. Report on the Chogabon site, a new source of obsidian artifacts in west-central Iran. IAOS Bulletin.

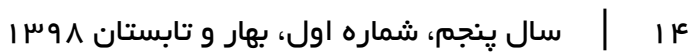


2010; 42:9-12.

[23] Abedi A. A review of obsidian studies in Iran, provenance the source and prehistoric obsidian artifacts, researches and questions. Journal of Research on Archaeometry. 2015; 1(1):55-85.

[عابدى، اكبر. مرورى بر مطالعـات ابسـيدين در ايـران،

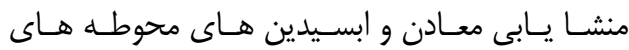

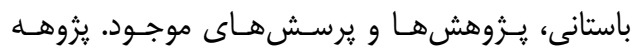

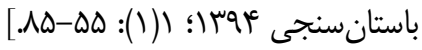

[24] Niknami KA, Amirkhiz AC, Glascock MD. Provenance studies of Chalcolithic obsidian artefacts from near Lake Urmia, northwestern
Iran using WDXRF analysis. Archaeometry. 2010 Feb;52(1):19-30.

[25] Behrouzi, A., \& Amini Azar, R. (1992). 1:100000 scale Sarab quadrangle, GSI, Tehran.

[26] Potts PJ, West M, editors. Portable X-ray fluorescence spectrometry: Capabilities for in situ analysis. Royal Society of Chemistry; 2008.

[27] Eslami M. The Application of Portable XRF in Archaeometry and Cultural-Historical Materials. Journal of Research on Archaeometry. 2015. 1(1), 87-101. 